Luciana Mitsue Sakano Niwa

\title{
O senescente nipônico e o voluntariado
}

Dissertação apresentada ao Programa de Pós-Graduação em Enfermagem da Escola de Enfermagem da Universidade de São Paulo para obtenção do título de Mestre em Enfermagem

Área de concentração: Cuidado em Saúde

Orientadora: Prof. ${ }^{\text {a }}$ Dra ${ }^{\mathrm{a}}$. Suely Itsuko Ciosak

São Paulo 
AUTORIZO A REPRODUÇÃO E DIVULGAÇÃO TOTAL OU PARCIAL DESTE TRABALHO, POR QUALQUER MEIO CONVENCIONAL OU ELETRÔNICO, PARA FINS DE ESTUDO E PESQUISA, DESDE QUE CITADA A FONTE.

Assinatura:

Data:

\section{Catalogação na Publicação (CIP)}

Biblioteca "Wanda de Aguiar Horta"

\section{Escola de Enfermagem da Universidade de São Paulo}

Niwa, Luciana Mitsue Sakano

O senescente nipônico e o voluntariado / Luciana Mitsue Sakano Niwa. São Paulo, 2017.

$87 \mathrm{p}$.

Dissertação (Mestrado) - Escola de Enfermagem da Universidade de São Paulo.

Orientadora: Prof. ${ }^{a}$ Dr. ${ }^{\text {a }}$ Suely Itsuko Ciosak

Área de concentração: Cuidado em Saúde

1. Envelhecimento. 2. Trabalho voluntário. 3. Motivação. 4. Enfermagem. I. Título. 
Nome: Luciana Mitsue Sakano Niwa

Título: O senescente nipônico e o voluntariado

Dissertação apresentada ao Programa de Pós-Graduação em Enfermagem da Escola de Enfermagem da Universidade de São Paulo para obtenção do título de Mestra em Enfermagem.

Aprovado em:

\section{Banca examinadora:}

Orientador: Profa. Dra. Suely Itsuko Ciosak.

Instituição: EEUSP- USP

Assinatura:

Prof. Dr. Instituição:

Julgamento: Assinatura:

Prof. Dr. Instituição:

Julgamento: Assinatura:

Prof. Dr. Instituição:

Julgamento: Assinatura:

Prof. Dr. Instituição:

Julgamento: Assinatura: 


\section{DEDICATÓRIA}

A Deus e só a Ele sejam dadas toda honra, louvor e glória para sempre.

A todos os voluntários do Projeto Lírios do Campo por estarem juntos nessa "caminhada", em especial ao Sr. Alberto Hasegawa (in memorian). 


\section{AGRADECIMENTOS}

Primeiramente a Deus por ter permitido que eu chegasse até aqui e por ter colocados pessoas maravilhosas em meu caminho, sem as quais este estudo não seria possível.

Agradeço a colaboração de professores, familiares e amigos, em especial:

A Prof.a. Dra. Suely Itsuko Ciosak, minha querida orientadora, por me conduzir nesta jornada e contribuir para o meu crescimento profissional e pessoal de maneira suave e assertiva.

A Prof.a. Aparecida Yoshie Yoshitome, razão da minha vinda a São Paulo.

A Prof.a. Dra. Yeda Aparecida de Oliveira Duarte por ter sido a porta de entrada a pós-graduação da EEUSP.

Aos amigos da pós-graduação pelas parcerias e almoços divertidos que suavizaram os momentos de estresse.

Aos amigos voluntários do Projeto Lírios do Campo pela participação no estudo e pelas orações, que não foram poucas, para a conclusão da dissertação.

Aos amigos de "Beverly" e Nanci por todo apoio e torcida desde o processo seletivo, comemorações do exame de qualificação, etc.

Aos irmãos da Igreja Metodista Livre com os quais pude dividir as preocupações e multiplicar a alegria.

Ao meu marido Nozomu pela parceria e apoio nessa caminhada.

A minha filha Julia companheira das madrugadas.

Aos meus pais Gilda e Douglas (in memorian) e meu irmão Juliano, por tudo o que sou.

Aos meus sogros Mika e Akio Niwa pelas orações e por cuidarem da Julia na minha ausência e também por me lembrarem que "é Deus quem efetua em vocês tanto o querer quanto o realizar, de acordo com a boa vontade dele" Filipenses $2: 13$ 
E, finalmente, a Lilica, minha cachorra que está deitada em meus pés enquanto estou escrevendo estes agradecimentos.

Que Deus abençoe ricamente a cada um de vocês! 
Sakano Niwa, LM. O senescente nipônico e o voluntariado. São Paulo: Escola de Enfermagem, Universidade de São Paulo; 2017.

\section{RESUMO:}

Introdução: O envelhecimento populacional é um fato inexorável tanto em países desenvolvidos como em países em desenvolvimento. Além do controle das doenças crônicas, manutenção da autonomia e independência, é preciso manter o idoso ativo e inserido na sociedade. Para muitos, a velhice tem seu marco inicial na aposentadoria pois é o momento em que há uma reflexão sobre o que fazer, qual o seu espaço na família e na sociedade. O trabalho voluntário tem permitido que os idosos se sintam úteis, permaneçam ativos e inseridos na sociedade. Objetivo: conhecer os motivos que levaram um grupo de senescentes de origem japonesa, evangélicos a serem voluntários em um projeto para idosos com limitações. Metodologia: estudo prospectivo, descritivo, sob os pressupostos da pesquisa quantitativa e qualitativa realizado com voluntários idosos de ambos os sexos, do Projeto Lírios do Campo, desenvolvido em uma igreja cristã japonesa da cidade de São Paulo. Resultados: a entrevista com dezesseis voluntários mostrou o predomínio (75\%) do sexo feminino e a média de idade foi de 70 anos. A maioria $(81,25 \%)$ dos voluntários tinham ensino superior completo, eram aposentados e relatavam presença de doença. A percepção do que é o idoso foi pessimista e marcada pela dependência para $56 \%$ dos voluntários, entretanto, os mesmos tinham uma visão positiva do próprio envelhecimento, já 44\% mostrou uma visão realista do envelhecimento sendo que a expectativa do próprio envelhecimento é a mesma em relação ao que é o idoso. Através da análise de conteúdo dos discursos, segundo Bardin e o uso do software Alceste, foi possível apreender que os motivos levaram os senescentes a se tornarem voluntários, classificados em três categorias: 1 . Deus (pelo chamado divino e disseminação do Evangelho), 2. Projeto (sentimento de pertencimento e de utilidade) e, 3. Valores (relacionados a vivencias familiares e gratidão, principalmente relacionado a mãe). Conclusão: para os senescentes do Projeto Lírios do Campo, os motivos que os tornaram voluntários estão ligados a um sentido de vida, que por serem cristãos, esse significado é servir a Deus, com atitudes que o demonstrem, através dos cuidados aos idosos 
portadores de limitações. Pertencer ao projeto é o modo de servir a Deus, seja pela afinidade com idosos, com a cultura japonesa ou por se tornarem referência e sentirem-se úteis. Os valores relacionados a vivencia de cuidar da mãe ou de algum familiar idoso, além de inspiração, também, foi uma forma de compartilhar suas experiencias e de retribuição. Conhecer os motivos que levaram os senescentes a se tornarem voluntários, numa instituição evangélica, mostrou que a influência da cultura nipônica se justapôs a evangélica quando buscam o sentimento de utilidade e servilismo ao ajudar o próximo, principalmente o idoso. Esses achados contribuíram não só para entender a dinâmica deste projeto, mas como enfermeiros, orientar novas iniciativas de trabalhos onde os idosos tenham papel fundamental, contribuindo com a sociedade e ao mesmo tempo, tornandoos úteis, produtivos e felizes.

Descritores: envelhecimento, trabalho voluntário, enfermagem, motivação. 
Sakano Niwa, LM. The Japanese senescent and volunteering. São Paulo: School of Nursing, University of São Paulo; 2017.

\begin{abstract}
Introduction: Population aging is an inexorable fact in both developed and developing countries. Besides controlling chronic diseases, maintaining autonomy and independence, it is necessary to keep the elderly active and inserted in society. For many, old age has its starting point in retirement because it is the moment in which there is a reflection on what to do, what its space in the family and in society. Voluntary work has allowed the elderly to feel useful, to remain active and inserted in society. Objective: The present study aims to know the reasons that led a group of senescent to be volunteers in a project for the elderly with limitations. Method: This is a prospective, descriptive study under the assumptions of the quantitative and qualitative research carried out with sixteen elderly volunteers of both sexes, of the Lilies of the Field Project, inserted in a Japanese Christian church in the city of São Paulo. Results: There was a predominance $(75 \%)$ of females and mean age was 70 years. The majority $(81.25 \%)$ of the volunteers had completed higher education, were retired and reported the presence of disease. The perception of the elderly was pessimistic and marked by dependence on $56 \%$ of the volunteers, however, they had a positive view of aging itself. For $44 \%$, a realistic view of aging is pointed out, and the expectation of aging itself is the same as that of the elderly. The reasons that led the senescent to become volunteers were related in three categories: 1. God, by calling and spreading the Gospel, 2. Project linked to the issues of belonging and feeling useful, finally, 3. Values related to experiences relatives taking care of the mother or taking the example of the grandmother as inspiration. Conclusion: for the senescent of the Lilies of the Field Project, the motives that made them voluntary are linked to a sense of life, which because they are Christians, this meaning is to serve God, with attitudes that demonstrate it, through the care of the elderly with limitations. Belonging to the project is the way of serving God, whether by affinity with the elderly, with Japanese culture or by becoming a reference and feeling useful. The values related to the experience of caring for the mother or some elderly relative, as well as inspiration, were also a
\end{abstract}


way of sharing their experiences and retribution. Knowing the reasons that led the senescent to become volunteers in an evangelical institution showed that the influence of Japanese culture juxtaposed with the evangelical when they seek the sense of usefulness and servility in helping others, especially the elderly. These findings contributed not only to understanding the dynamics of this project, but as nurses, to guide new work initiatives where older people play a fundamental role, contributing to society while making them useful, productive and happy.

KEYWORDS: Aging, volunteer work, nursing, motivation. 


\section{SUMÁRIO}

\section{APRESENTAÇÃO}

1. INTRODUÇÃO

1.1 ENVELHECIMENTO POPULACIONAL

1.2 APOSENTADORIA E VOLUNTARIADO

1.3 JUSTIFICATIVA

1.4 REFERENCIAL TEÓRICO

2. OBJETIVOS

2.1 OBJETIVO GERAL

2.2 OBJETIVOS ESPECÍFICOS

3. METODOLOGIA

3.1 CENÁRIO DO ESTUDO

3.2 POPULAÇÃO

3.3 INSTRUMENTO DE COLETA DE DADOS

3.4 COLETA DE DADOS

3.5 ASPECTOS ÉTICOS E LEGAIS

3.6 ANÁLISE DOS RESULTADOS

4. RESULTADOS

4.1 CARACTERÍSTICAS SOCIODEMOGRÁFICAS 4.2 ESTADO DE SAÚDE

4.3 PERCEPÇÕES DO ENVELHECIMENTO

4.4 PERCEPÇÕES DO VOLUNTARIADO

4.4.1 DEUS

4.4.1.a CHAMADO DIVINO

4.4.1.b DISSEMINAÇÃO DO EVANGELHO

4.4.2 PROJETO

4.4.2.a PERTENCIMENTO

4.4.2.b SENTIR-SE ÚTIL

4.4.3 VALORES

4.4.3.a FAMÍLIA

4.4.3.b GRATIDÃO
1

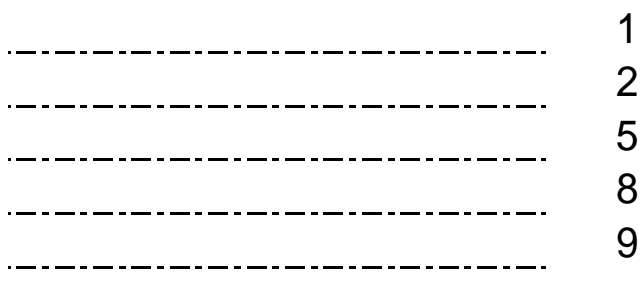

11

12

12

13

14

17

17

19

20

21

23

24

26

28

29

31

32

33

34

34

35

36

37

38 
5. DISCUSSÃO 39

5.1 CARACTERÍSTICAS SOCIODEMOGRÁFICAS

5.2 ESTADO DE SAÚDE 41

5.3 PERCEPÇÕES DO ENVELHECIMENTO 42

5.4 PERCEPÇÕES DO VOLUNTARIADO 45

6. CONSIDERAÇÕES FINAIS 49

7. REFERÊNCIAS BIBLIOGRÁFICAS 52

APÊNDICES

Questionário

TCLE 62

ANEXOS 65 


\section{APRESENTAÇÃO:}

Participar da criação de um projeto de trabalho voluntário para idosos foi um divisor de águas em minha vida.

Sou enfermeira especialista em gerontologia e geriatria e, na ocasião, eu trabalhava em um hospital de alta complexidade da cidade de São Paulo, onde não faltavam recursos humanos, materiais, padrões e selos de segurança e qualidade reconhecidos internacionalmente.

Porém, no dia-a-dia, me deparava com a assistência voltada cada vez mais a protocolos institucionais do que ao paciente, trabalhava com pessoas que visavam o marketing pessoal e eram voltadas para o sucesso próprio. Estava bastante desestimulada e perguntando a razão de ter estudado tanto para virar uma mera "preenchedora" de protocolos.

Em uma das poucas vezes que fui a igreja evangélica japonesa, em 2007 houve um convite aberto para os interessados a participar de um projeto para idosos, que me encheu de alegria e entusiasmo e ao chegar em casa enviei um e-mail me colocando à disposição do projeto. Assim, ingressei neste grupo, mas minha participação inicial era virtual por causa de meu vínculo empregatício.

Quando finalmente tive férias, consegui me reunir com o grupo, que para minha surpresa e deles, também, só eu não era idosa ou aposentada.

Após um ano de estudos sobre o envelhecimento e suas necessidades, conhecemos algumas iniciativas de outros grupos que cuidavam de idosos. Com este proposito surgiu a ideia de formalizar o grupo, redigimos as diretrizes para o seu funcionamento e o batizamos com o nome de "Projeto Lírios do Campo, em referência a passagem do Evangelho de Lucas, capitulo 12, versículo 27: "olhai os lírios do campo, como eles crescem; não trabalham, nem fiam; e digovos que nem ainda Salomão, em toda a sua glória, se vestiu como um deles"; para demonstrar que apesar de nossas limitações e incapacidades, Deus tem o mesmo amor e o mesmo cuidado. 
Conhecendo melhor o grupo e atuando com maior proximidade junto a estes idosos, fui aprendendo o sentido do amor, assim como, cada um se engajou neste trabalho voluntário.

Essas histórias ricas de significados me despertaram o desejo de conhecer melhor cada uma destas trajetórias e escrever sobre elas. Fato este que se aguçou com a morte repentina de um voluntário no ano de 2015, cuja história muito me comoveu e reforçou o desejo de conhecer por que um grupo de idosos se tornaram voluntários para um projeto voltado a idosos com limitações. 

1. INTRODUÇÃO 


\section{INTRODUÇÃO}

\subsection{ENVELHECIMENTO POPULACIONAL}

Envelhecimento populacional é um fenômeno universal e acontece tanto em países desenvolvidos como em países em desenvolvimentos por causa da transição demográfica e epidemiológica. A expectativa de vida ao nascer, no mundo, passou de 47,7 anos em 1950 para 67,9 anos em 2010 (World Bank, 2015).

Estima-se que em 2025 serão 1,2 bilhões de idosos no planeta e as estatísticas sugerem que este valor aumente para 2 bilhões por volta do ano de 2050 (Brasil, 2005). O processo de envelhecimento esteve associado, inicialmente, às regiões mais desenvolvidas. Países europeus estão entre aqueles com maior proporção de idosos em relação às demais faixas etárias. Nações como Itália, Japão e Alemanha terão em 2025 um terço da população formada por indivíduos idosos (Brasil, 2005).

De acordo com as projeções da Organização das Nações Unidas (ONU) em 2009, uma a cada nove pessoas no mundo tem 60 anos e mais e estima-se um crescimento de um para cada cinco em 2050. Em 2008, nos países desenvolvidos, a população idosa correspondia a $21 \%$ ou 264 mil pessoas e nos países em desenvolvimento $8,5 \%$ ou 475 mil pessoas (ONU,2009).

O envelhecimento populacional é um fato inexorável e apesar de diferenças culturais que tenho convivido, por ser brasileira com ascendência japonesa e trabalhando com a comunidade nipônica, observo que este envelhecimento tanto para a população japonesa quanto a brasileira acontecem com velocidade acelerada.

O Brasil vive a transição demográfica e epidemiológica, marcada pelo aumento rápido e acelerado da população idosa, contudo ainda não é um país rico. Segundo os dados do Censo 2010, a população com 60 anos ou mais de idade representavam $10,7 \%$ de toda a população, a expectativa de vida era de 73,1 anos de vida e estima-se que, em 2030, a população brasileira será aproximadamente de 223 milhões de pessoas, dos quais $13,44 \%$, ou seja, aproximadamente 30 milhões de indivíduos terão 60 anos ou mais (IBGE, 2014). 
No Japão, a população com 60 anos ou mais representava $23 \%$ da população total em 2010 e a expectativa de vida ao nascer era de 83 anos (World Bank, 2015). O aumento da longevidade no Japão teve início em 1950, com a implementação de programas eficazes de controle de doenças infecciosas, a promulgação de 32 leis de saúde nos dez anos que se seguiram ao final da Segunda Guerra Mundial e posteriormente, a implementação de medidas preventivas contra doenças não transmissíveis e a manutenção de um sistema de saúde universal equitativo e acessível, garantiu benefícios para a saúde da população japonesa em todo o período de transição epidemiológica ( Ikeda N, Saito, Kondo, Inoue, Ikeda S, Satoh, et al.,2011).

À semelhança, no Brasil, com o intuito de propor um caminho para um envelhecimento com qualidade, a Secretaria dos Direitos Humanos em parceria com outros ministérios e órgãos buscou implementar ações que favoreçam a promoção da inclusão e independência da pessoa idosa pelo maior tempo possível. Podemos identificar marcos Legais Nacionais que favoreceram o percurso de amadurecimento sobre a questão do envelhecimento, como a própria Constituição Federal de 1988 e a Política Nacional do Idoso, estabelecida em 1994 (Lei 8.842). As instituições governamentais brasileiras, organismos da sociedade civil e movimentos sociais conquistaram uma gama de leis, decretos, propostas e medidas que estabelecem direitos voltados para a pessoa idosa, referenciados pelo Plano de Ação internacional para o Envelhecimento (Brasil, 2016).

Contabilizam-se conquistas democráticas importantes, como a criação do Conselho Nacional dos Direitos do Idoso (CNDI) em 2002 e a elaboração e publicação do Estatuto do Idoso em 2003, que regulamenta os direitos das pessoas com idade igual ou superior a 60 anos. Entre os anos de 2006 e 2011 foram realizadas, no Brasil, três Conferências Nacionais de Direitos da Pessoa Idosa que contaram, de forma progressiva, com uma expressiva participação da sociedade civil e do governo, cuja proposição destacam-se o Plano de Ação para o Enfrentamento da Violência contra a Pessoa Idosa (2004); a reedição da Política Nacional de Saúde da Pessoa Idosa (2006); o II Plano de Ação para o Enfrentamento da Violência contra a Pessoa Idosa (2007) (Brasil, 2016). 
Infelizmente não nos preparamos para este período de transição apesar de saber a velocidade do envelhecimento da população brasileira e suas repercussões em todas as áreas do conhecimento. Nesse contexto, a preocupação com as condições necessárias à manutenção da qualidade de vida das pessoas idosas tem crescido e os temas relacionados a políticas públicas, a ações de proteção e cuidado específicos para idosos vêm adquirindo relevância inédita na agenda pública (Beltrão, Camarano e Kanso, 2004).

As principais preocupações relacionadas ao envelhecimento segundo Camarano, Kanso e Mello (2004) são as doenças crônicas que provocam incapacidade e dependência. A sobrecarga da família, a pressão sobre as políticas públicas, especialmente as relativas a seguridade social, benefícios previdenciários e assistenciais e serviços de saúde (Borges, Campo e Silva, 2015).

Apesar do bom desempenho na promoção de saúde da população, o Japão um dos países com população mais longevas, também, tem desafios, onde as três principais causas de morte, câncer, doença cardíaca e doença cerebrovascular representam $50 \%$ do risco de morrer e a redução da mortalidade por doenças não transmissíveis é a chave para prolongar a longevidade da população (Reich, Ikegami, Shibuya e Takemi, 2011).

Outro desafio são as várias formas de demência, amplamente discutidas no simpósio sobre envelhecimento realizado em Tóquio (2015), especialmente o estigma e discriminação que a doença traz para o indivíduo que por vezes, reluta em aceitar a própria demência. A família também, é afetada e muitos abrem mão de seus empregos para cuidar de seus idosos (Mc Curry, 2015).

Embora do ponto de vista de envelhecimento populacional intenso e acelerado, o Brasil e o Japão sejam semelhantes, cada país tem suas dificuldades, desafios específicos e recursos tecnológicos e governamentais distintos, porém em todos eles cabe a seguinte reflexão: De que forma esses idosos podem continuar ativos e inseridos de forma atuante na sociedade, principalmente após a aposentadoria?

A aposentadoria pode representar um marco de envelhecimento, pois é o momento que deixam o mercado de trabalho e podem se sentir improdutivos e até mesmos deslocados em relação a sociedade. Alguns idosos, em virtude da 
aposentadoria começam a desempenhar novos papeis na família como cuidar dos netos e até mesmo ser a principal fonte de renda da família.

Verifica-se que, mesmo com todas essas legislações e programas a favor da proteção do envelhecimento, ainda existem lacunas para os idosos desfrutarem de seu envelhecimento.

Assim, considerando a importância dos idosos estarem ativos e produtivos, mesmo com a aposentadoria, encontrar espaços de atuação em atividades remuneradas ou não, podem trazer benefícios físicos e psíquicos, no enfrentamento do envelhecimento.

Vários estudos têm apontado o voluntariado como uma oportunidade dos idosos, aproveitarem os seus conhecimentos, a disponibilidade, reconhecimento pessoal e a necessidade de sentir útil (Moniz e Araújo, 2006).

\subsection{APOSENTADORIA E O VOLUNTARIADO}

Segundo Bragança (2004), os significados do trabalho e da aposentadoria são postulados pela lógica do capitalismo, onde o indivíduo é valorizado pelo que produz. Assim, muitas vezes, a aposentadoria é percebida como uma atuação de desvalorização em consequência do fim da participação no processo de produção capitalista, criando a ideia de pobreza e incapacidade e aumentando o imaginário social de estigma de inutilidade do idoso.

As pessoas vivem a experiência da aposentadoria de maneira diferenciada em consequência dos diversos significados que dão para o trabalho e para a aposentadoria. Para alguns, essa experiência é indesejada, já para outros a aposentadoria é um evento aguardado na vida, pois é a oportunidade de desfrutar de todo esforço vivido, ou seja, o descanso e o lazer (Sabate, 2016).

Um ensaio publicado em 2014, descreveu fatores de risco e de proteção que dificultam ou facilitam a adaptação do indivíduo à aposentadoria. Destacamse como fatores de risco: poucos recursos financeiros, doenças, ausência de rede social e laços familiares, falta de planejamento e aposentadoria involuntária. 
E como fatores de proteção, ter auto eficácia, maior renda, educação, saúde, lazer, praticar atividades físicas, ser casado, ter rede social e realizar trabalho voluntário (Leandro-Franca e Murta, 2014).

$\mathrm{Na}$ literatura há um consenso de que o trabalho voluntário é qualquer atividade onde a pessoa oferta, livremente, o seu tempo para beneficiar outras pessoas, grupos ou organizações, sem retribuição monetária (Souza, 2008).

O trabalho voluntário, do mesmo modo que o remunerado, abrange uma complexa esfera de atividades, sendo definido pela Lei 9.608/1998 como a atividade não remunerada prestada por pessoa física a entidade pública ou privada de qualquer natureza, de fins não lucrativos, que tenha objetivos cívicos, culturais, educacionais, científicos, recreativos ou de assistência social, inclusive mutualidade. Deve ter as seguintes características:

1. Ser voluntário, ou seja, não pode ser imposto ou exigido como contrapartida de algum benefício concedido pela entidade ao indivíduo ou a sua família;

2. Ser gratuito;

3. Ser prestado pelo indivíduo, isoladamente, e não como subcontrato de uma organização da qual o indivíduo faça parte e, portanto, seja pela mesma compelido a prestá-lo; e

4. Ser prestado para entidade governamental ou privada, sendo que estas devem ter fim não lucrativo e voltado para objetivos públicos (Brasil, 1998).

O trabalho voluntário pode ser formal, que inclui tarefas efetuadas para com organizações, ou informal, como ajudar a um vizinho ou familiar (Fischer, Mueller e Cooper, 1991).

Para entender o desenvolvimento do voluntariado no Brasil, é preciso conhecer um pouco de sua origem e vinculação. Ele teve início com a fundação da Santa Casa de Misericórdia de Santos em 1543, neste período a religião e a caridade estavam fortemente ligadas e centradas na área de saúde. Em 1935, inicia-se a colaboração do governo junto as instituições filantrópicas e houve uma atenção maior aos trabalhadores sem carteira assinada, informais e desempregados, dando continuidade à política de caridade cristã e a 
benemerência como os principais reguladores das ações voluntarias e filantrópicas. Na década de 70, surgem as primeiras organizações não governamentais (ONGs) no país, fomentadas por organizações europeias com o objetivo de promover projetos de desenvolvimento no Terceiro Mundo (Souza, Lauert e Hilleshein, 2011).

No início da década de 80, o movimento voluntariado passa a ser reavaliado e questionado politicamente por estar associado a atividades político-partidárias voltadas à democratização e aos direitos humanos. Um novo modelo de trabalho voluntário foi proposto pelo sociólogo Herbert de Souza, marcado pela atuação de indivíduos motivados a exercer a cidadania em prol de causas comunitárias, que revitalizou, em âmbito nacional, a conscientização para a solidariedade, a vontade de atuar para resolução de problemas imediatos e o aumento de reinvindicações junto ao governo (Ação Voluntária, 2016; Instituto Brasil Voluntário, 2016).

Relembrar a história das ações voluntárias é essencial para entender o avanço da participação da sociedade civil na solução de problemas públicos, ajudando a consolidar a democracia e a cidadania no país. Atualmente, as antigas concepções de voluntariado como a caridade, o assistencialismo ou a militância política, estão sendo superados por um entendimento de ação cívica engajada com a real transformação de nossa sociedade (Ação Voluntária, 2016; Instituto Brasil Voluntário, 2016).

O centro de voluntariado de São Paulo, mostrou que em 2013, 25\% da população brasileira declarou que faz ou fez serviço voluntário e dos que eram voluntários na ocasião, 16\% tinham de 18 a 24 anos, $22 \%$ de 30 a 39 anos e $19 \%$ de 40 a 49 anos. As atividades voluntárias eram destinadas em sua maioria (39\%) a crianças e adolescentes e uma minoria (13\%) aos idosos, não mostrando a inserção dos idosos nestas atividades.

Um estudo sobre trabalho voluntário realizado por idosos na pastoral da criança mostrou que dos 197.945 voluntários, 15,3\% tinham 60 anos e mais, associando o voluntariado a sentimentos religiosos, ocupação do tempo livre, 
ajuda a causas importantes, contribuindo para um sentimento de bem-estar psicológico (Labegalini, Uema, Carreira, Higarashi e Baldissera, 2015).

Alguns autores, mostraram que o voluntariado religioso apresenta influência positiva sobre a felicidade, mas não sobre a saúde auto relatada, porém, traz mais benefício para a saúde mental, quando comparado ao voluntariado para outras causas (Binder e Freytag, 2013; Musick e Wilson, 2003)

$\mathrm{Na} 2^{\circ}$ Assembleia Mundial Sobre o Envelhecimento (2002), publicou uma versão do Plano de Ação Internacional para o Envelhecimento cujo propósito é garantir que as pessoas possam envelhecer com seguridade, dignidade e saúde, participando ativamente da sociedade e do seu desenvolvimento. Propõe que uma sociedade para todas as idades deva oportunizar a contribuição das pessoas idosas para a sociedade, no intuito de que sua colaboração social e econômica não se limite à produção econômica, sugerindo atividades como cuidados a membros da família, a manutenção dos lares e a realização de trabalho voluntário na comunidade, entre outras (ONU, 2002).

Souza e Lauert (2008) apontam o trabalho voluntário como uma alternativa para a promoção de saúde de idosos por terem maior satisfação com a vida, menos sintomas depressivos e avaliação positiva da vida quando comparados com idosos que não o realizam.

A Organização Mundial da Saúde (OMS) considera o voluntariado como elemento importante para a qualidade de vida e bem-estar na velhice, sendo uma proposta de envelhecimento ativo (OMS, 2005).

\subsection{JUSTIFICATIVA}

Considerando o aumento do número de idosos no Brasil e a escassez de oportunidades para que possam manter-se ativos e produtivos na sociedade; considerando que a comunidade japonesa é reservada e voltada para ações entre si; considerando a disposição e a responsabilidade demonstrados por idosos em atividades sociais e solidárias, considerando, ainda que, idosos que realizam trabalho voluntário tem melhor qualidade der vida (Souza, Lauert e 
Hillshein, 2011), emergiu a proposição de investigar os motivos que levam os idosos desta comunidade a se tornarem voluntários em um projeto voltados a idosos com algumas limitações.

\subsection{REFERENCIAL TEÓRICO}

A Motivação deriva do latim movere que significa mover e refere-se, em ciências humanas, a um impulso interno que leva a ação. O estudo da motivação envolve a busca de princípios que auxiliam a compreender, por que seres humanos e animais em determinadas situações, escolhem, iniciam e mantem determinadas ações (Rudolph, 2003).

Motivação também é uma ideia do direcionamento momentâneo do pensamento, da atenção, da ação a um objetivo visto pelo indivíduo como positivo. Esse direcionamento ativa o comportamento e engloba conceitos diversos como anseio, desejo, vontade, esforço, sonho, esperança entre outros (Rheinberg, 2000).

A teoria de Maslowé uma das teorias mais conhecidas de motivação. Segundo Maslow (1970), a motivação é o resultado dos estímulos que agem sobre os indivíduos, ou seja, necessita que haja uma ação para que um estímulo aconteça.

Essa teoria funciona como um ciclo motivacional. Uma vez que o ciclo não se realiza, a frustração pode se manifestar de diversas maneiras que variam de comportamento ilógico, agressividade, nervosismo, insônia, distúrbios circulatórios e digestivos, apatia, falta de interesse, pessimismo, entre outros.

Mesmo quando a necessidade não é satisfeita, não significa que o indivíduo permanecerá frustrado eternamente. A necessidade será transferida ou compensada de alguma maneira. Daí percebe-se que a motivação é um estado cíclico e constante na vida pessoal (Maslow, 1970).

Maslow (1970) apresenta uma teoria da motivação organizada em cinco níveis hierarquicamente, onde a base é composta por:

1. necessidades fisiológicas ou básicas, seguida por

2. necessidades de segurança,

3. necessidades sociais ou afetivo-social, 
4. necessidades de status ou autoestima e no topo,

5. necessidade de auto realização, que envolve desafios mais complexos, trabalho criativo, realização do próprio potencial e de autodesenvolvimento contínuo.

Nesse sentido, os idosos talvez, estariam buscando necessidades sociais ou até mesmo escalando o topo da pirâmide em busca de auto realização pessoal.

Já para o Dr. Burkard Siervers (1990), professor de economia da Universidade de Wuppertal, Alemanha, a motivação é relacionada aos mecanismos intrapsíquicos do mundo interior sem maiores ligações com 0 mundo social exterior.

Segundo Siervers (1990) a motivação passou a ser apenas um tópico quando o sentido do próprio trabalho desapareceu. A perda do sentido do trabalho ocorreu por causa da crescente divisão e fragmentação do trabalho. Como consequencia, as teorias motivacionais tem se transformado em sucedâneos na busca da motivação.

Com a teoria motivacional, o homem foi reduzido a um homuncúlo em relação a posição inicial de ter sido criado a imagem e semelhança de Deus. A busca de teorias perde o foco no homem. As abordagens científicas explicam o ser humano em termo mecânicos, como entidades desconectas de sentido e com preocupações que não vão além da satisfação das necessidades individuais primárias. (Siervers, 1990).

Entretanto, o que se entende pelo estabelecimento de uma relação entre o sentido do trabalho e da vida, é que o trabalho só pode ter significado se for visto não unicamente como uma dimensão da instituição empregadora, mas também, como uma parte da vida individual e coletiva. O significado do trabalho só pode ser compreendido além do referencial da vida, precisa ser qualificado a partir da realidade da finitude humana, para dar sentido a sua utilidade (Sievers, 1990).

Desse modo, podemos inferir que os idosos tenham uma percepção real do sentido da vida e do trabalho e o voluntário traz a essência do significado de trabalho. 


\section{OBJETIVOS}

\subsection{OBJETIVO GERAL:}

- Descrever os motivos que levaram os idosos de origem japonesa a exercerem atividades de voluntariado em um projeto voltado para idosos.

\subsection{OBJETIVOS ESPECÍFICOS:}

- Descrever as características sócio demográficas dos idosos que exercem atividades de voluntariado.

- Conhecer a auto percepção dos voluntários, sobre a própria saúde.

- Identificar se os idosos voluntários se percebem como idosos.

- Identificar os fatores motivacionais do voluntariado com esse grupo de idosos. 
3.METODOLOGIA 


\section{METODOLOGIA:}

Estudo prospectivo, descritivo, sob os pressupostos da pesquisa quantitativa e qualitativa. Os dados quantitativos permitiram contextualizar os idosos voluntários em sua forma de viver, já os dados qualitativos contemplam o universo de significados, motivos, crenças e aspirações do ser humano, que não podem ser descritos com variáveis (Minayo, 2012).

A adoção desta metodologia possibilitou responder melhor ao objetivo do presente estudo que é o de captar, entre os idosos, o que os levaram a se tornarem voluntários, em especial em um projeto que cuida de idosos com alguma limitação, contemplando seus papéis e as relações de importância frente ao trabalho desenvolvido (Ângelo et al., 2009).

\subsection{CENÁRIO DE ESTUDO}

O estudo foi realizado no projeto Lírios do Campo da Igreja Metodista Livre, no Bairro Saúde, na cidade de São Paulo. O projeto foi criado em 2007 por um casal da igreja, com objetivo de proporcionar, quinzenalmente, um dia de folga para o cuidador de idosos, portador de comprometimento cognitivo e físico leve e moderado. Para tal, os idosos são trazidos para a igreja, ficam sob os cuidados do Projeto, durante a primeira e terceira sextas-feiras do mês.

O projeto iniciou com um convite aos interessados em trabalhar com idosos e estes com base em princípios bíblicos, se reuniram por um ano para desenvolver, estruturar, planejar, capacitar e estagiar, objetivando atender da melhor maneira possível aos idosos que ficariam sob seus cuidados.

Do ponto de vista financeiro, é autossustentável, sem fins lucrativos, porém para cobrir os gastos com materiais lúdicos e de cuidados é cobrado uma mensalidade no valor de $\mathrm{R} \$ 28,00$ e uma taxa de $R \$ 12,00$ por encontro, para subsidiar as refeições.

Foram adotadas no projeto, as seguintes definições:

- Usuário: o idoso que desfruta do projeto.

- Cuidador: o familiar responsável pelo cuidado do idoso.

- Voluntário: Os que atuam de maneira direta no projeto. 
Os critérios de participação do usuário no projeto são: presença de cuidador, vontade do idoso em participar e competência do grupo em cuidar. Desse modo, o idoso e o cuidador participam de dois encontros e decidem se querem participar do projeto. Se decidirem participar, é realizado uma entrevista com o cuidador para conhecer as características sócio demográficas do idoso, hábitos alimentares e vesico-intestinais, atividades de vida diária, problemas de saúde, medicações em uso, convênio médico e o contato do cuidador.

A capacidade de atendimento do projeto é de 18 idosos, todas as vagas estão preenchidas e existe uma fila de espera. Todos têm ascendência japonesa e a maioria tem alguma limitação física e/ou cognitiva. Há predomínio de mulheres e a mais idosa tem 103 anos. Os cuidadores são familiares e nem todos frequentavam a igreja.

As atividades ocorriam entre 9:00 e 15:00 horas e incluiam: aferição de pressão arterial, frequência cardíaca e temperatura; músicas e louvores entoados acompanhados ao som do teclado; meditação onde o pastor traz uma passagem rápida da Bíblia; ginástica corporal sentada e com os dedos; atividades lúdicas adaptadas; origami; etc., que são dirigidas e acompanhadas pelos voluntários.

As refeições eram feitas ao estilo da culinária japonesa, adaptadas com consistências macias, tamanhos diferentes de cortes e temperos para atender as necessidades dos usuários. Ao todo, são três refeições: lanche de boasvindas, almoço e café de despedida.

Cada usuário recebe uma agenda do projeto onde consta o calendário com as datas dos encontros e uma anotação referente ao dia com informações de todas as atividades desenvolvidas para conhecimento da família. A agenda é o meio de comunicação entre os cuidadores e o projeto e é preenchida próximo ao final das atividades.

Além dos encontros, temos um passeio fora da cidade de São Paulo que possibilita maior integração entre os usuários, familiares e voluntários. Também são realizadas palestras de interesse do cuidador, como por exemplo o envelhecimento ativo e a doença de Alzheimer, geralmente no segundo semestre, em um sábado. 
Os voluntários são divididos em 3 grupos:

1. Voluntários: Os que trabalham diretamente nas atividades, transferências posturais e no atendimento as necessidades fisiológicas dos usuários.

2. Voluntários da refeição: Os que trabalham na cozinha na elaboração do cardápio e realização da refeição. Algumas voluntárias têm curso especifico de culinária japonesa para idosos.

3. Voluntários mantenedores: os que contribuem exclusivamente com doações materiais ou financeiras. Estes não foram objetos desse estudo.

Os critérios de inclusão para o voluntário são: preferencialmente terem vínculo com a igreja, serem indicados por outros voluntários e disposição para planejar e participar das atividades junto aos usuários. Da mesma forma que o usuário, o candidato a voluntário, também, participa de dois encontros antes de sua inserção no projeto, e pode escolher entre as atividades junto aos usuários ou na preparação das refeições. Ao todo são 22 voluntários divididos entre 0 cuidado com os idosos limitados e as atividades da refeição.

Ao término das atividades, os voluntários se reúnem para avaliação das atividades, refeições oferecidas no dia, percepções sobre facilidades e dificuldades dos usuários, após o qual é programado o próximo encontro, elaborada a escala de voluntários, bem como planejamento de comemorações, visitas e passeios. Tudo é documentado e arquivado na igreja.

O projeto Lírios do Campo começou a funcionar somente em maio de 2008 e em 2011 foi premiado na Câmara Municipal de São Paulo, no dia do voluntário, por seu trabalho no sentido de prover um descanso para o cuidador de idosos.

Ao longo desses 10 anos de existência, 3 voluntários partiram para a morada celestial sendo dois homens e uma mulher.

Atualmente acompanha outras igrejas que desejam trabalhar com idosos nos Estados de São Paulo e Paraná e pretende ampliar as atividades para três encontros/mês para o ano de 2018. 


\subsection{POPULAÇÃO}

Os sujeitos da pesquisa foram 16 senescentes voluntários formais do Projeto Lírios do Campo, que atuavam nas atividades ou na cozinha e atenderam aos seguintes critérios: ter 60 anos e mais, ambos os sexos, com participação mínima de três meses no projeto e que concordem em participar da pesquisa.

Para assegurar o anonimato dos participantes, estes foram identificados com a letra $\mathrm{V}$ de 'voluntário' seguidos de números arábicos, de acordo com a sequência de realização das entrevistas.

\subsection{INSTRUMENTO DE COLETA DE DADOS:}

Para atender aos objetivos propostos foi elaborado um questionário (Apêndice A) para apreender o perfil do idoso e suas características sócio demográficas. Para melhor conhecer o perfil dos idosos voluntários serão realizadas avaliações de aspectos psico-cognitivos com auxílio de instrumentos como segue: o Mini-Mental (Anexo A) e a Escala de Depressão Geriátrica de Yesavage (Anexo $B$ ), disponíveis e validados para uso em pesquisas e na prática clínica com idosos no Brasil.

Estes instrumentos fazem parte da segunda e última edição do Manual de Assistência de Enfermagem a Saúde da Pessoa Idosa da Secretaria Municipal de Saúde de São Paulo (São Paulo, 2012).

Os instrumentos utilizados estão descritos a seguir.

A. Questionário composto por perguntas abertas e fechadas e dividido em 4 itens (Apêndice A):

1. Condições sócio demográficas: serão abordadas questões referentes a idade em anos, sexo, estado civil, escolaridade, geração, ocupação, aposentadoria, religião e crença.

A idade foi analisada como variável quantitativa continua e posteriormente transformada em três categorias: 60-69 anos (idoso jovem), 79-79 anos (idoso), 
80 e mais (idosos velhos), de acordo com Berquó (2004), classificação esta adotada para países em desenvolvimentos. Néri (2001) também usa de uma classificação semelhante justificada pelo alongamento do ciclo vital humano, onde a velhice passa a comportar subdivisões que atendem às necessidades organizacionais da ciência e da vida social.

Estado civil foi transformado em variável dicotômica onde os casados foram agrupados em com companheiro (a) e os viúvos, separados/divorciados e solteiros em sem companheiro (a).

Uma participante, em virtude de seu período escolar ter sido no Amazonas e de seus pais acreditarem que o Japão sairia vitorioso da Guerra, não frequentou a escola, contudo uma professora foi contratada para ensinar as crianças em casa. Essa participante foi alfabetizada em casa e considerada como fundamental incompleto.

Tanto a aposentadoria como o tempo de aposentadoria foram tratados como variáveis dicotômicas, sendo o tempo classificado como menor e maior que 15 anos.

2. Estado de Saúde: percepção de saúde, presença de doença, uso de medicamentos e análise psico-cognitiva através de escalas consagradas para população idosa.

3. Percepção do envelhecimento: duas questões, uma sobre como o idoso é e outra quando eu for idoso eu serei, para avaliar percepção positiva ou negativa do envelhecimento. Quanto maior a distância entre o que os idosos idealizam para si e o que realmente é o idoso pior a percepção do envelhecimento (Paschoal, Pacheco, Jacob, Litvoc, 2007)

4. Percepções sobre o trabalho voluntário e sua participação no projeto: abordarão a história no projeto, motivos que os levaram a participar, conceitos de voluntário.

B. Mini-exame do estado mental (Anexo 1):

É um breve questionário de 30 pontos elaborados por Folstein e colaboradores em 1975 para detectar a deterioração cognitiva. 
O mini mental é composto por questões agrupadas em 7 categorias com a finalidade de avaliar funções cognitivas específicas: orientação para o tempo (5 pontos), orientação para o local (5 pontos), registro de três palavras (3 pontos), atenção e cálculo (5 pontos), memorização das três palavras (3 pontos), linguagem (8 pontos) e capacidade visual (1 ponto). A pontuação é dada levando-se em consideração a escolaridade. Escores muito baixos associados aos outros testes sugerem encaminhamento para uma avaliação mais específica (São Paulo, 2012).

Por ser de fácil aplicação é o teste de rastreio mais utilizado para avaliar a função cognitiva no mundo. Fornece informações sobre os seguintes domínios: orientação temporal, espacial, memória imediata e de evocação, calculo, linguagem-nomeação, repetição, compreensão, escrita e cópia do desenho.

Não há consenso quanto aos pontos de corte para declínio cognitivo no Brasil. A escolaridade tem recebido atenção especial, sendo alvo de análises efetuadas com diferentes amostras, visando-se principalmente a adequação dos pontos de corte (Melo, Barbosa, 2015), no entanto para este estudo, as notas de corte foram sugeridas segundo o Caderno de Atenção Básica (2006), onde são atribuídos 28 pontos para oito anos e mais de escolaridade, 24 para quatro a sete anos de escolaridade, 23 de um a três anos e 19 para analfabetos. Foi estabelecido, como indicativo de declínio cognitivo, um escore igual ou inferior a 23 pontos (Melo, Barbosa, 2015; Brasil, 2006).

\section{Escala de Depressão Geriátrica de Yesavage (Anexo 2):}

Em 1983, Yesavage e colaboradores desenvolveram e validaram um instrumento de triagem para depressão conhecido como escala de depressão geriátrica. A escala possui uma versão longa, com 30 questões e uma curta com 15 questões. Ambas são validadas internacionalmente e amplamente utilizadas na avaliação geriátrica global para a detecção de depressão no idoso. O escore acima de 5 sugere depressão (Paradela, Lourenço e Veras, 2005).

Neste estudo será adotada a versão reduzida composta por 15 perguntas, já que o tempo gasto com sua aplicação pode ser reduzido. 


\subsection{COLETA DE DADOS:}

A coleta de dados foi feita no período de abril a maio de 2017 , por meio de entrevista individual realizada pela pesquisadora na igreja Metodista Livre da Saúde ou na residência do participante. As entrevistas foram agendadas com antecedência para que os participantes pudessem organizar suas agendas.

As perguntas fechadas foram preenchidas durante a entrevista e as respostas as questões norteadoras, referentes a história no projeto, foram gravadas. Todos os 16 voluntários elegíveis leram e assinaram o Termo de consentimento livre e esclarecido - TCLE (Apêndice B).

\subsection{ASPECTOS ÉTICOS E LEGAIS:}

De acordo com a determinação da Resolução CNS/MS 466 de 12 de dezembro de 2012, que regulamenta a ética em pesquisa envolvendo seres humanos no Brasil, o projeto foi submetido ao Comitê de Ética em Pesquisa da Escola de Enfermagem da Universidade de São Paulo, parecer número 2.026.658 aprovado (Anexo 3), a autorização do Projeto Lírios do Campo da Igreja Metodista Livre da Saúde (Anexo 4) também aprovada.

O TCLE foi entregue aos entrevistados elegíveis que aceitaram participar da pesquisa, sendo respeitada a confidencialidade e sigilo sobre as informações obtidas, bem como a garantia da liberdade de retirar-se da pesquisa a qualquer momento, sem qualquer prejuízo, punição ou atitude preconceituosa. O TCLE, elaborado em duas vias, sendo a primeira via do entrevistado e a segunda arquivada pelo pesquisador.

Quanto aos benefícios que essa pesquisa proporciona, o principal é o incentivo da participação de idosos em trabalhos voluntários. Para os participantes da pesquisa, falar sobre a experiência vivida oferece a possibilidade de reorganizar os pensamentos, elaborar significados de sua 
experiência, trazer a lembrança momentos agradáveis, o que muitos consideram bastante proveitoso. Por outro lado, outros podem não se sentir tão confortáveis.

Os riscos que esta pesquisa oferece aos participantes estão relacionados exclusivamente ao campo do bem-estar emocional, por ser uma investigação sobre experiência vivida.

Todos os participantes após a leitura e assinatura do TCLE, consentiram em participar da pesquisa.

\subsection{ANÁLISE DOS DADOS}

Os dados quantitativos foram submetidos a análise descritiva e apresentados em tabelas de frequência para caracterizar a população do estudo.

Os dados qualitativos foram analisados de acordo com os preceitos análise de conteúdo de Bardin (2011) que se fundamenta em um conjunto de técnicas de análise de comunicação visando obter, por procedimentos sistemáticos e objetivos, indicadores que permitam a inferência de conhecimentos relativos às condições de produção/recepção destas mensagens, sob os pressupostos da motivação.

Os dados a respeito do trabalho voluntário foram submetidos à análise de conteúdo temática, que consiste em três fases:

1.Pré análise dos dados, Exploração do material e formação de categoriais e Tratamento das categorias obtidas e interpretação. Na pré análise dos dados foi realizado o primeiro contato com o material, a transcrição das entrevistas e organização dos dados para formulação de ideias iniciais, e leitura flutuante para observar a homogeneidade e consistência dos relatos.

2. Na exploração do material foram feitas leituras profundas e exaustiva do material e formação de categorias com auxílio de canetas marcadoras coloridas para identificar as informações semelhantes que depois agrupa-las.

3. Tratamento das categorias obtidas e interpretação, após a obtenção das categorias mais significativas de acordo com os relatos dos voluntários, 
resolvemos usar o software Alceste que permite extrair as estruturas mais significativas de um texto para comparar e complementar as categorias.

O ALCESTE versão 2012, é um software de análise de dados textuais que surgiu no Centro Nacional Frances de Pesquisa científica. A análise de dados textuais ou a estatística textual é a metodologia que visa descobrir a informação essencial de um texto. Essa metodologia, em forte crescimento, encontra aplicações em todas as áreas onde se lida com sequências de texto com 0 objetivo de extrair o significado (Camargo, 2005 e Azevedo, Costa e Miranda, 2013).

O software Alceste permite realizar de maneira automática a análise de entrevistas, perguntas abertas de pesquisas socioeconômicas, compilações de textos diversos, etc. O objetivo é quantificar um texto para extrair as estruturas mais significativas e para isso estabelece semelhanças entre os segmentos e hierarquias de classes de palavras contidas no interior de um corpus através do coeficiente de associação qui-quadrado. Para o pesquisador, estas categorias não são o fim em si, mas estabelecem pressupostos de interpretação (Camargo, 2005 e Azevedo, Costa e Miranda, 2013).

A análise de conteúdo de Bardin e a utilização do Alceste permitiu maior clareza na definição das categorias dos discursos dos voluntários. 


\section{RESULTADOS}

Buscando encontrar os motivos que levaram os idosos de origem nipônica a serem voluntários no Projeto Lírios do Campo, encontramos 22 voluntários dos quais, 17 tinham 60 anos e mais. Estes foram contatados para participar da entrevista, porém uma foi excluída por, ainda, estar em período de treinamento.

Para melhor exposição dos dados, estes serão apresentados em quatro tópicos: características sociodemográficos, estado de saúde e percepções sobre o envelhecimento e o voluntariado.

\subsection{CARACTERÍSTICAS SOCIODEMOGRÁFICAS}

Entre os 16 voluntários participantes, houve predomínio do sexo feminino $(75 \%)$ em todas as faixas etárias. A média de idade foi de 70 , desvio padrão de 6,7 anos, idade mínima de 60 e máxima de 83 anos. Metade dos voluntários era idosos jovens (60-69 anos), $38 \%$ idosos ( $70-79$ anos) e apenas $12 \%$ eram idosos velhos (80 anos e mais). Os voluntários de sexo masculino compuseram $25 \%$ da população (Tabela 1).

Apenas dois voluntários tinham nacionalidade japonesa, os demais eram descendentes e pertenciam a segunda geração de japoneses no Brasil (Tabela 1).

A maioria $(81,25 \%)$ dos voluntários tinham ensino superior completo. Verificamos que aqueles que não chegaram a completar o ensino fundamental, estava mais presente nas faixas acima dos 70 anos e nas mulheres (12,5\%) (Tabela 1).

Quase todos os idosos $81,25 \%$ (13) eram aposentados, sendo que só as mulheres não o eram e destas uma continuava no mercado de trabalho (Tabela 1).

Os voluntários quase todos $81,25 \%$ (13) tinham companheiros, sendo que só três mulheres não os tinham, sendo uma solteira, uma viúva e outra separada. 
No geral moravam com seus familiares, apenas duas mulheres (a solteira e a separada) moravam sozinhas (Tabela 1 ).

Apenas uma mulher solteira não tinha filhos, os demais os tiveram. A média de filhos foi de aproximadamente 3 , desvio padrão de 1,4, número máximo de 5 e mínimo de 1 filho.

Apesar de todos os voluntários terem mais de 60 anos, apenas 7 tinham netos, os outros aguardavam viver essa experiência.

Tabela 1 - Características sociodemográficas dos voluntários do Projeto Lírios do Campo, segundo sexo e idade. São Paulo, 2017.

\begin{tabular}{|c|c|c|c|c|c|c|c|c|c|c|c|c|}
\hline \multirow{3}{*}{ Variáveis } & \multicolumn{4}{|c|}{60 a 69 anos } & \multicolumn{4}{|c|}{70 a 79 anos } & \multicolumn{4}{|c|}{80 e mais } \\
\hline & \multicolumn{2}{|c|}{ Masc } & \multicolumn{2}{|c|}{ Fem } & \multicolumn{2}{|c|}{ Masc } & \multicolumn{2}{|c|}{ Fem } & \multicolumn{2}{|c|}{ Masc } & \multicolumn{2}{|c|}{ Fem } \\
\hline & $\mathbf{n}$ & $\%$ & $\mathbf{n}$ & $\%$ & $\mathbf{n}$ & $\%$ & $\mathbf{n}$ & $\%$ & $\mathbf{n}$ & $\%$ & $\mathbf{n}$ & $\%$ \\
\hline \multicolumn{13}{|l|}{ Nacionalidade } \\
\hline Brasileiro & 1 & 6,3 & 7 & 44,0 & 1 & 6,3 & 4 & 25,0 & 1 & 6,3 & 1 & 6,3 \\
\hline Japonês & 0 & 0,0 & 0 & 0,0 & 1 & 6,3 & 0 & 0,0 & 0 & 0,0 & 0 & 0,0 \\
\hline \multicolumn{13}{|l|}{ Escolaridade } \\
\hline fundamental incompleto & 0 & 0,0 & 0 & 0,0 & 0 & 0,0 & 1 & 6,3 & 1 & 6,3 & 1 & 6,3 \\
\hline Superior completo & 1 & 6,3 & 7 & 43,8 & 2 & 12,5 & 3 & 18,8 & 0 & 0,0 & 0 & 0,0 \\
\hline \multicolumn{13}{|l|}{ Aposentado } \\
\hline Não & 0 & 0,0 & 2 & 12,5 & 0 & 0,0 & 1 & 6,3 & 0 & 0,0 & 0 & 0,0 \\
\hline Sim & 1 & 6,3 & 5 & 31,3 & 2 & 12,5 & 3 & 18,8 & 1 & 6,3 & 1 & 6,3 \\
\hline \multicolumn{13}{|l|}{ Tempo aposentadoria } \\
\hline menor que 15 anos & 1 & 6,3 & 3 & 18,8 & 1 & 6,3 & 0 & 0,0 & 0 & 0,0 & 0 & 0,0 \\
\hline maior que 15 anos & 0 & 0,0 & 2 & 12,5 & 1 & 6,3 & 3 & 18,8 & 1 & 6,3 & 1 & 6,3 \\
\hline \multicolumn{13}{|l|}{ Estado Civil } \\
\hline Com companheiro (a) & 1 & 6,3 & 6 & 37,5 & 2 & 12,5 & 2 & 12,5 & 1 & 6,3 & 0 & 0,0 \\
\hline Sem companheiro (a) & 0 & 0,0 & 1 & 6,3 & 0 & 0,0 & 2 & 12,5 & 0 & 0,0 & 1 & 6,3 \\
\hline \multicolumn{13}{|l|}{ Mora sozinho (a) } \\
\hline Não & 1 & 6,3 & 6 & 37,5 & 2 & 12,5 & 3 & 18,8 & 1 & 6,3 & 1 & 6,3 \\
\hline Sim & 0 & 0,0 & 1 & 6,3 & 0 & 0,0 & 1 & 6,3 & 0 & 0,0 & 0 & 0,0 \\
\hline Total $n=16 \quad 100 \%$ & 1 & 6,3 & 7 & 43,8 & 2 & 12,5 & 4 & 25,0 & 1 & 6,3 & 1 & 6,3 \\
\hline
\end{tabular}

Quanto a religiosidade, por estarem vinculados a uma igreja específica, todos são evangélicos e consideravam este fato muito importante. Frequentavam a igreja pelo menos uma vez por semana, procurando viver suas vidas de acordo com os preceitos da igreja. 


\subsection{ESTADO DE SAÚDE}

A percepção de saúde foi classificada como boa em $38 \%$, regular para $56 \%$ e ruim para apenas $6,25 \%$ dos voluntários. Ao compararem a saúde há um ano atrás, $19 \%$ considerou a condição de saúde atual melhor, $62 \%$ igual e $19 \%$ pior. A piora do estado de saúde comparada há um ano atrás, foi referida apenas pelas mulheres (Tabela 2).

Ao compararem a sua saúde com a de outras pessoas da mesma idade, $44 \%$ acreditam ter melhor saúde, $44 \%$ saúde igual aos contemporâneos e, somente, $12 \%$ acreditam ter pior saúde. O grupo que considerou a saúde melhor quando comparado aos seus contemporâneos, foram os homens na faixa etária de 70-79 além do grupo mais longevo (Tabela 2).

A presença de doença foi relatada por $81 \%$ dos voluntários, destes $69 \%$ apresentavam até dois tipos de doenças e faziam uso de até 4 medicamentos diários. O grupo que apresentavam três ou mais doenças (31\%) utilizavam cinco medicamentos e mais, que foi observada na faixa etária dos 70 aos 79 anos (Tabela 2).

As doenças mais frequentes foram: hipertensão arterial, referida por $56 \%$ dos voluntários, seguida doença ósteo-articulares $(37,5 \%)$, diabetes $(18,75 \%)$, Síndrome do Pânico e hipercolesterolemia (12,5\%), Parkinson, Câncer de mama, Cardiopatia e Incontinência urinária com $6,25 \%$ cada uma.

Apesar da idade, chamou atenção que $19 \%$ não referiram doença, sendo dois idosos jovens e uma mulher na faixa etária dos 70 a 79 anos (Tabela 2). 
Tabela 2 - Percepções de saúde dos voluntários do Projeto Lírios do Campo, segundo sexo e idade. São Paulo, 2017.

\begin{tabular}{|c|c|c|c|c|c|c|c|c|c|c|c|c|}
\hline \multirow{3}{*}{ Variáveis } & \multicolumn{4}{|c|}{60 a 69 anos } & \multicolumn{4}{|c|}{70 a 79 anos } & \multicolumn{4}{|c|}{80 e mais } \\
\hline & \multicolumn{2}{|c|}{ Masc } & \multicolumn{2}{|c|}{ Fem } & \multicolumn{2}{|c|}{ Masc } & \multicolumn{2}{|c|}{ Fem } & \multicolumn{2}{|c|}{ Masc } & \multicolumn{2}{|c|}{ Fem } \\
\hline & $\mathbf{n}$ & $\%$ & $\mathbf{n}$ & $\%$ & $\mathbf{n}$ & $\%$ & $\mathbf{n}$ & $\%$ & $\mathbf{n}$ & $\%$ & $\mathbf{n}$ & $\%$ \\
\hline \multicolumn{13}{|l|}{ Percepção da saúde/ atual } \\
\hline Boa & 0 & 0,0 & 3 & 18,7 & 1 & 6,3 & 0 & 0,0 & 1 & 6,3 & 1 & 6,3 \\
\hline Regular & 1 & 6,2 & 4 & 25,0 & 1 & 6,3 & 3 & 18,8 & 0 & 0,0 & 0 & 0,0 \\
\hline Ruim & 0 & 0,0 & 0 & 0,0 & 0 & 0,0 & 1 & 6,3 & 0 & 0,0 & 0 & 0,0 \\
\hline \multicolumn{13}{|l|}{ Percepção da saúde/passado } \\
\hline Melhor & 0 & 0,0 & 1 & 6,2 & 0 & 0,0 & 1 & 6,3 & 1 & 6,3 & 0 & 0,0 \\
\hline lgual & 1 & 6,2 & 5 & 31,2 & 2 & 12,5 & 2 & 12,5 & 0 & 0,0 & 0 & 0,0 \\
\hline Pior & 0 & 0,0 & 1 & 6,3 & 0 & 0,0 & 1 & 6,3 & 0 & 0,0 & 1 & 6,3 \\
\hline \multicolumn{13}{|l|}{ Percepção saúde/comparada } \\
\hline Melhor & 0 & 0,0 & 1 & 6,3 & 2 & 12,5 & 2 & 12,5 & 1 & 6,3 & 1 & 6,3 \\
\hline lgual & 1 & 6,2 & 5 & 31,3 & 0 & 0,0 & 1 & 6,3 & 0 & 0,0 & 0 & 0,0 \\
\hline Pior & 0 & 0,0 & 1 & 6,3 & 0 & 0,0 & 1 & 6,3 & 0 & 0,0 & 0 & 0,0 \\
\hline \multicolumn{13}{|l|}{ Presença de doença } \\
\hline Sim & 0 & 0,0 & 6 & 37,5 & 2 & 12,5 & 3 & 18,8 & 1 & 6,3 & 1 & 6,3 \\
\hline Não & 1 & 6,2 & 1 & 6,3 & 0 & 0,0 & 1 & 6,3 & 0 & 0,0 & 0 & 0,0 \\
\hline \multicolumn{13}{|l|}{ Quantidade de doenças } \\
\hline Até 2 patologias & 0 & 0,0 & 5 & 31,3 & 1 & 6,3 & 1 & 6,3 & 1 & 6,3 & 1 & 6,3 \\
\hline De 3 e mais patologias & 0 & 0,0 & 1 & 6,3 & 1 & 6,3 & 2 & 12,5 & 0 & 0,0 & 0 & 0,0 \\
\hline \multicolumn{13}{|l|}{ Uso de medicação } \\
\hline $\operatorname{Sim}$ & 0 & 0,0 & 6 & 37,5 & 2 & 12,5 & 3 & 18,8 & 1 & 6,3 & 1 & 6,3 \\
\hline Não & 1 & 6,3 & 1 & 6,3 & 0 & 0,0 & 1 & 6,3 & 0 & 0,0 & 0 & 0,0 \\
\hline \multicolumn{13}{|l|}{ Quantidade de medicações } \\
\hline Até 4 medicamentos & 0 & 0,0 & 4 & 25,0 & 1 & 6,3 & 2 & 12,5 & 0 & 0,0 & 1 & 6,3 \\
\hline De 5 e mais medicamentos & 0 & 0,0 & 2 & 12,5 & 1 & 6,3 & 1 & 6,3 & 1 & 6,3 & 0 & 0,0 \\
\hline Total $(n=16 \quad 100 \%)$ & 1 & 6,3 & 7 & 43,8 & 2 & 12,5 & 4 & 25,0 & 1 & 6,3 & 1 & 6,3 \\
\hline
\end{tabular}

A média de escore da aplicação do Mini-mental foi de 28,7 pontos com desvio padrão de 1,85, valor máximo de 30 e valor mínimo de 23 e revelou que $94 \%$ dos participantes ficaram com escore esperado para o nível de escolaridade do grupo, portanto não apresentavam déficit cognitivo. Apenas uma mulher teve escore de 23 pontos e apresentou déficit de memória, que não influenciava na atividade exercida no grupo.

Segundo a GDS, apenas um voluntário apresentou escore sugestivo de depressão. 


\subsection{PERCEPÇÃO SOBRE O ENVELHECIMENTO:}

A percepção do envelhecimento sobre o que é o idoso, foi negativa para $56 \%$, mas tinham uma visão positiva do próprio envelhecimento. Já $44 \%$ dos voluntários tinham uma visão realista do envelhecimento pois para eles o que entendiam por ser idoso e a expectativa do próprio envelhecimento foram as mesmas.

No Quadro 1 estão listadas as opiniões dos voluntários sobre o que é o idoso e quantas vezes a palavra apareceu. Percebe-se que a perda da capacidade funcional relacionada a dependência física foi a mais mencionada, seguida de valores como experiente e sábio. Carência e humor depressivo, também, foram relatados e uma minoria atribuiu valor cronológico e características físicas como cabelos brancos ao envelhecimento (Quadro 1).

Quadro 1- Percepção dos voluntários do Projeto Lírios do Campo sobre o que o idoso é. São Paulo, 2017.

$\begin{array}{llll}\text { Capacidade funcional } & \text { Valores } & \text { Humor } & \text { Características físicas } \\ \text { Dependente (10) } & \text { Experiente (6) } & \text { Carente (5) } & \text { Idade avançada (2) } \\ \text { Doente (4) } & \text { Sábio (2) } & \text { Depressivo (3) } & \text { Cabelo branco (1) } \\ \text { Independente/ativa (3) } & \text { Carinhoso (2) } & \text { Feliz (2) } & \\ \text { Memória diminuída (1) } & \text { Pouco atrativo (2) } & \text { Ansioso (2) } \\ & \text { Respeitado (1) } & \text { Teimoso (1) } \\ & \text { Dedicada (1) } & \text { Reclamão (1) } \\ & \text { Não se relaciona com família (1) }\end{array}$

A percepção do próprio envelhecimento foi positiva e a expectativa é de uma velhice independente, feliz, com idosos agradáveis e carinhosos. Nesse sentido, apenas na autopercepção apareceram descrições relacionadas a espiritualidade relacionadas a Deus e a fé (Quadro 2).

Quadro 2 - Percepção dos voluntários do Projeto Lírios do Campo sobre o próprio envelhecimento. São Paulo, 2017.

$\begin{array}{llll}\text { Capacidade funcional } & \text { Humor } & \text { Valores } & \text { Espiritualidade } \\ \text { Independente (11) } & \text { Feliz (6) } & \text { Agradável/Carinhosa (5) } & \text { Pessoa de fé (1) } \\ \text { Dependente (3) } & \text { Ansiosa (3) } & \text { Altruista (2) } & \text { Obediente a Deus (1) } \\ \text { Saudável (3) } & \text { Teimosa (2) } & \text { Bom convívio familiar (2) } & \text { Servir melhor a Deus (1) } \\ \text { Memória diminuída (1) } & \text { Chato (1) } & \begin{array}{l}\text { Precavida financeiramente(1) } \\ \end{array} & \\ & & \text { Sábio (1) } & \\ & & \text { Dedicada (1) }\end{array}$




\subsection{PERCEPÇÕES SOBRE O VOLUNTARIADO}

A partir das entrevistas com os idosos para capturar as percepções sobre 0 voluntariado, foi possível apreender os seguintes significados: ajudar o próximo (75\%), sentir-se útil $(50 \%)$, contribuir com a sociedade (25\%), compartilhar experiências e ocupação de tempo (12,5\%).

Dos 16 participantes, sete já estiveram envolvidos com outros trabalhos voluntários e destes apenas três continuavam nas duas instituições.

Os motivos apontados que os levaram a participar de outros voluntariados foram: sentir-se útil, ajudar os outros, manter vínculo com a cultura japonesa, gostar de fazer artesanato, ter afinidade com idosos, gostar da área de finanças e administração, justificativas que muitas vezes se assemelham ao significado do voluntariado. Um voluntário, alegou que sua participação nesta atividade contribuía, para melhorar a pontuação na avaliação de desempenho na empresa, na qual mantinha vínculo.

Pouco mais da metade (56\%) dos voluntários estavam no projeto desde o princípio em 2007 e 44\% começaram a participar a partir de 2010.

No projeto, $56 \%$ dos voluntários exerciam atividades de cuidado aos idosos e 44\% atuavam na cozinha, organizando o cardápio de culinária japonesa ou preparando os alimentos.

Algumas dificuldades foram apontadas pelos voluntários como as relacionadas a comunicação, o desenvolvimento do cuidado, a morte e a evolução da própria idade.

As maiores dificuldades enfrentadas pelos voluntários no cuidado aos idosos estavam relacionadas a comunicação, devido ao déficit de fluência na língua japonesa e as características culturais, de serem introvertidos. As famílias dos frequentadores, as vezes mostram-se fechadas, dificultando a comunicação com os voluntários, que muitas vezes não conseguiam informar a involução dos idosos no decorrer do tempo.

Além das relacionadas, a comunicação intragrupo dos voluntários, que às vezes refletia no desenvolvimento das atividades do projeto. 
Houve ainda, o receio de cuidar dos idosos da maneira adequada, de acordo com as suas expectativas e a dos usuários. A morte de alguns idosos cuidados, também, foi descrita como uma dificuldade, pelo vínculo estabelecido.

E evolução da idade dos voluntários também era um limitante, embora nem sempre verbalizado, porém influía na busca de novos desafios ou novas atividades dentro do projeto que melhor adequassem às suas habilidades com o avançar da própria idade.

Para maioria dos voluntários que atuavam na cozinha não foi relatado nenhuma dificuldade em suas atividades, talvez porque elas tinham afinidade com a culinária japonesa, onde a refeição tem um certo destaque.

Cantar, contemplar a alegria dos idosos, a gratidão dos cuidadores familiares e a conversão ao cristianismo, são as maiores satisfações relatadas pelos voluntários.

Buscando aprimorar a análise dos conteúdos dos discursos dos voluntários, buscou-se algumas ferramentas que permitissem extrair estruturas mais significativas, não só a análise de discurso de Bardin (2011), tendo associado o software Alceste (2012) do qual foi possível identificar as palavras mais frequentes: ideia $(0,56)$, convite $(0,51)$, família $(0,51)$, área $(0,51)$, (servir $(0,44)$, Deus $(0,41)$, japonês $(0,36)$ mãe $(0,33)$, sonho $(0,29)$ e voluntÁrio $(0,33)$.

A partir da frequência das palavras e da análise do conteúdo de cada discurso, emergiram 3 categorias com suas subcategorias e unidades de registro, descritas no Quadro 3. 


\begin{tabular}{|c|c|c|}
\hline Quadro 3 - Motivo & $\begin{array}{l}\text { varam os senescentes tornar } \\
\text { Lírios do Campo.São Paul }\end{array}$ & $\begin{array}{l}\text { em-se voluntários no Projeto } \\
\text {, 2017. }\end{array}$ \\
\hline Categorias & Subcategorias & Unidades de Registro \\
\hline & Chamado Divino & $\begin{array}{l}\text { Vontade de Deus } \\
\text { Chamado/capacitação de Deus }\end{array}$ \\
\hline & Disseminação do Evangelho & $\begin{array}{l}\text { Conversão dos idosos } \\
\text { Divulgar o Cristianismo }\end{array}$ \\
\hline & Pertencimento & $\begin{array}{l}\text { Visibilidade } \\
\text { Afinidade } \\
\text { Bom relacionamento entre voluntários } \\
\text { Cultura japonesa }\end{array}$ \\
\hline 2. Projeto & Sentir-se útil & $\begin{array}{l}\text { Desejo de ajudar } \\
\text { Entender melhor os idosos/mãe }\end{array}$ \\
\hline 3. Valores & Família & $\begin{array}{l}\text { Mãe } \\
\text { Avó } \\
\text { Conjuge }\end{array}$ \\
\hline & Gratidão & Retribuição \\
\hline
\end{tabular}

Foram identificados como categorias os temas centrais: 1. Deus, 2 Projeto e 3. Valores, cada um com suas subcategorias e unidades de registro.

\subsubsection{Deus}

Aspectos espirituais/ religiosos foram identificados como categoria dominante nos discursos dos voluntários e foi nominada de Deus. Essa categoria já era esperada em virtude do Projeto ser vinculado a Igreja Metodista Livre e todos os voluntários serem membros da igreja.

Para os cristãos desta igreja, há um só Deus vivo e verdadeiro, o Criador e conservador de todas as coisas e é Ele que orienta não só a inserção no projeto, mas através de suas ações a serem exemplos de dedicação e disseminação do evangelho.

Nesta categoria, duas subcategorias foram identificadas nas falas dos senescentes: o Chamado Divino e Disseminação do Evangelho (Quadro 3). 


\subsection{1.a CHAMADO DIVINO:}

Nessa subcategoria foram identificadas como unidades de registro fazer a vontade de Deus e Chamado/Capacitação de Deus (Figura 3), que tem um apelo forte da própria religião. Trata-se de atuar no Projeto, realizando o propósito de Deus, cujo poder, sabedoria e bondade são eternos (Igreja Metodista Livre Concílio Nikkey, 2011).

As falas abaixo traduzem como foi o chamado Divino:

"Foi em 1996 que Deus colocou em meu coração sobre esse projeto, [...]Se Deus colocou no meu coração, quem vai começar esse trabalho é Deus, então realmente eu orei muito mais e quando na devocional que eu faço todo dia, Deus me colocou um versículo que está em Provérbios e fala que " faça o que Deus colocou no seu coração. Deus há de realizar! Realmente Deus foi bom! Desde que colocou o sonho no meu coração, Ele colocou muitas pessoas experientes e durante esse relacionamento com as pessoas, fora isso Ele me fez estudar, né, muitos cursos da associação nipo-brasileira" (V8)

"O Lírios foi em função dela [esposa], em relação a cuidadores, foi minha ideia, então conjugamos os dois [... ]Mas é isso aí, em tudo Deus tem trabalhado. São coisas que eu acho que para o cristão é um processo e para as pessoas de fora é um processo sim, acho que não vão entender essas coisas. " (V7)

Esses relatos descrevem que o Chamado de Deus aconteceu como um sonho, colocado no coração e compartilhado com outras pessoas, onde 0 mesmo Deus que chama para o propósito, também o realiza, recruta e capacita as pessoas envolvidas, de maneira processual.

Outro relato envolvendo a vontade de Deus foi:

" Convidaram [a participar do projeto] e eu disse não. [...] olha, para falar a verdade eu não tenho simpatia por velhinhos. Daí nesse dia eu estava lendo Gêneses a parte do Abraão que Deus pediu o Isaac, eu li tantas vezes essa passagem e acho que tudo bem, né. Depois eu fiquei com aquilo na cabeça. Puxa vida! Duas vezes por mês, 1 x/semana por que eu não vou aceitar? E é para Deus, né. Eu acho que fui mesmo tocada por Deus. Se Deus me tocou eu preciso fazer alguma coisa. [...] como eu senti que era Deus que tinha me proposto isso, eu vim com a maior alegria. " (V15)

Fazer a vontade de Deus nem sempre é fácil, pode significar abrir mão da zona de conforto, esse discurso mostra que apesar da pessoa não ter afinidade 
com idosos e nem vontade de participar do projeto, quando se sentiu tocada por Deus, reconsiderou sua resposta e entendeu que se tratava de um chamado Divino e resolveu atender prontamente.

\subsubsection{B DISSEMINAÇÃO DO EVANGELHO}

Disseminar ou propagar o evangelho é missão de todos os cristãos, conforme a Bíblia diz: "Ide por todo o mundo, pregai o evangelho a toda criatura." Marcos 16:15.

A conversão ao cristianismo é o principal objetivo de propagar o evangelho. É a passagem de criatura para filho de Deus e acontece quando o sujeito aceita a Cristo como Salvador e Senhor de sua vida. Este é um momento de muita alegria para os cristãos, pois se trata de entregar a vida para Cristo, ter seus pecados perdoados e reconciliar-se com Deus.

Alguns discursos revelam Deus como forma de conversão e, também, propagar o evangelho, como apresentamos abaixo:

\footnotetext{
"quando batizou, eu nem sabia que ela ia batizar. Cheguei aqui e o pastor falou: sua mãe vai batizar. Eu falei: imagina. Não ia batizar porque já era batizada no budismo. Não acredito! E não é que ela batizou? Nem os filhos sabiam! Nossa! Foi uma surpresa muito grande! " (V3)

"Não é um projeto frio, só cuidar por cuidar eu não ficaria. Para mudar a opinião do idoso em relação a igreja e em relação a Deus. O que me fez ficar foi o fundo evangelístico. " (V16)

"Eu vejo que todas essas atividades que partiram do voluntariado, estão ganhando pessoas para Cristo. " (V9)

"Quando aceitam a Jesus, então o batismo! Nossa! Se um a cada dois anos, apareceu uma pessoa que se converteu já valeu a pena! " (V16)
}

O primeiro discurso relata a surpresa da voluntária com a notícia do batismo de sua mãe. Alguns membros da igreja buscam a conversão de seus pais ou seus familiares para o Cristianismo e nesse sentido, o projeto Lírios do Campo pode ser um caminho para que os idosos tenham contato com o evangelho. 
Estes discursos revelam o quanto a evangelização e a conversão dos idosos usuários do projeto é importante para os voluntários. Não se trata apenas de aumentar o número de membros da igreja e sim de levar a Salvação e a promessa de vida eterna.

\subsubsection{PROJETO:}

Essa categoria abrange os significados que o Projeto Lírios do Campo tem para os voluntários. Suas subcategorias envolvem o pertencimento ao projeto e sentir-se útil (Quadro 3).

\subsection{2.a PERTENCIMENTO:}

Pertencer ao projeto é um motivo de bastante alegria, pois os voluntários se sentem importantes e acabam tendo visibilidade dentro da igreja, no sentido de se tornarem referências para as famílias que possuem idosos com limitações.

"[...] eu me sentia assim, uma peça importante no projeto. Por isso que eu falo, eu não marco as coisas na sexta feira do projeto porque eu acho importante, então dificilmente eu falto. " (V3)

Esta fala ilustra o compromisso e a importância de pertencer ao Projeto, onde a voluntária tem reservado as datas de atividade e procura não faltar.

É válido ressaltar que todos os voluntários, sem exceção, mencionaram pelo menos uma vez o nome do voluntário coordenador ou da voluntaria secretária em seus discursos, que os tornaram referências na busca de informações a respeito do projeto e/ou de algumas questões referentes aos idosos e cuidadores.

Outro ponto é que participar do projeto faz bem para o convívio social dos voluntários. A relação de amizade entre os voluntários, foi construída a partir do projeto, pois como a igreja possui muitos membros, a maioria não se conhecia anteriormente, conforme mostra o relato:

"Para mim é muito bom participar, conheci mais gente e converso com outras pessoas, em casa tem outras coisas, mas não tem com quem conversar. É muito bom para mim, distrai a cabeça. " (V11) 
Uma forma de pertencimento foi despertada pela afinidade com o propósito do Projeto, como os depoimentos abaixo:

"Um dia o Alberto foi lá na frente, no culto e chegou dizendo do projeto. Que eles queriam montar esse projeto voltado para os idosos e não só cuidar dos idosos, mais dar um dia para o cuidador. Eu achei interessante. " (V16)

"Eu achei interessante a proposta, [...] Porque eu já me sentia cuidadora. Nossa! Eu cuido da minha mãe! Eu cuido da minha sogra!! E realmente não é fácil. Precisa desse dia de descanso. " (V3)

Os discursos sobre o objetivo de dar um dia de descanso para o cuidador familiar de idosos, as vezes até se identificando como cuidadora fez com que os senescentes se tornassem voluntários.

O bom exemplo e relacionamento entre o grupo de voluntários, assim como o trabalho em equipe, fortalecem o pertencimento.

"Eu gosto muito, acho o ambiente muito agradável, a integração entre os voluntários eu acho maravilhoso. Todos acolhem a todos muito bem. Essa interação com pessoas mais novas, inclusive com crianças, eu acho muito legal participar do projeto. " (V9)

"Eu vejo também o $\mathrm{Sr} \mathrm{M}, \mathrm{Y}$ (outros voluntários homens) e isso também me incentivou, pela idade deles, a dedicação, O sr M (Voluntário com 80 anos), por exemplo, vem cedo e já deixa as cadeiras arrumadas, ele é um exemplo para mim. " (V6).

Rememorar a cultura dos ancestrais japoneses também influenciou no pertencimento e na participação dos voluntários.

"[...] primeiro, quando o Alberto foi lá na frente e disse o objetivo, eu me identifiquei pela situação. Situação que eu digo é que eu domino a língua japonesa e que Alberto falou dessa área de que seria na fala em japonês. Eu me identifiquei mais por isso. " (V4)

\subsection{2.b SENTIR-SE ÚTIL:}

Participar do voluntariado é uma via de mão dupla, pois ao mesmo tempo que significa ajudar ao próximo e a sociedade, conforme os próprios voluntários citaram, por outro lado também é uma maneira destes sentirem-se úteis. 
“É quando aparecer alguma coisa que eu possa ser útil, eu procuro estar ativo nesta área. " (V4)

"Ser voluntária é você contribuir com a sociedade de alguma maneira. " (V1)

"Voluntário seria um meio de encontrar um sentido de vida." (V7).

"É querer servir aos outros. Interagir com outras pessoas, sentir-se útil e também é uma doação muito gratificante. " (V9)

Os voluntários demonstraram, nas falas acima, o interesse em manteremse úteis e prestativos contribuindo com a sociedade ou servindo aos outros. Doar-se, contribuir, servir, interagir com as pessoas, sentir-se útil é gratificante para este grupo.

Ao ajudar no projeto, os voluntários sentiram-se úteis e interessados em aprender mais sobre envelhecimento, fato que repercutiu como um cuidado melhor para um parente e na desmistificação do receio/ preconceito de se interagir com idosos, como podemos verificar nos discursos abaixo:

"Eu fui entender mais a minha mãe, cuidando das outras. Com a mãe a gente fala: "ai como ela está chata" ou "faz sozinha", mas cuidando dos idosos aqui [no projeto], eu pensei: Nossa! Elas são dependentes! Elas precisam de alguém para conversar, (pausa). Eu falei: "Nossa! Eu preciso cuidar melhor da minha mãe! Se eu tenho paciência com as outras, eu tenho que ter paciência com a minha mãe. " (V3)

" [...]é coisa de Deus mesmo. Ele me conhece e sabe que eu não tenho jeito nenhum com os idosos. Tenho medo de idosos! Então, para mim cada dia é um aprendizado e lidar com idosa, agora, eu tenho o maior prazer. Eu venho cada dia com muita satisfação e faço com o maior prazer. "(v15).

\subsubsection{VALORES}

Nesta categoria foram identificados a importância dada a quem se tem estima, afeto, apreço e consideração. Família foi descrita como subcategoria juntamente com o sentimento de gratidão (Quadro 3). 


\subsection{3.a FAMÍLIA}

Nos discursos dos voluntários frequentemente nos deparamos com a menção das palavras mãe, avó, esposa, tias, membros femininos da família, talvez pelo fato da cultura japonesa as figuras masculinas serem responsáveis pelo sustento financeiro e manterem um certo distanciamento dos filhos que é traduzido em forma de respeito. Por outro lado, cabe as mães a educação dos filhos e o convívio mais próximo com a família.

A experiência de ter cuidado, vivenciado e restaurado o relacionamento com a mãe na finitude, também motivou os senescentes a se tornarem voluntários, como descrito nos discursos abaixo:

"Então, foi a minha mãe de 93 anos que eu perdi, né. E aí eu fiquei, nossa podia fazer alguma coisa para pessoas de idade né. " (V2)

"É mais ou menos um certo remorso assim de eu não ter me dado muito para a minha mãe. [...] 50 e tantos anos a vida toda aí é trabalhar, é estudar, é criar filhos e nunca tinha ficado muito tempo com ela (a mãe) conversando, no último ano dela foi que a gente mais se conversou a vida toda [...] e foi assim um modo de prolongar, vamos dizer, o ajudar para minha mãe, então eu vou ajudar nos Lírios. Faz de conta que são todas minhas mães [...] achei que eu poderia ajudar porque eu ajudava a minha mãe, ela começou a andar com o andador, ela foi ficando cada vez mais precisando mesmo de uma pessoa do lado e aí eu falei assim: "ah, eu vou ajudar sim. " (V1)

A convivência com a avó foi a fonte de inspiração e um exemplo aprendidos na infância, para trabalhar com idosos:

"Minha mãe tinha a saúde frágil, quem cuidou da minha irmã caçula fui eu e a minha avó estava sempre presente. Ela era uma pessoa dedicada e além de nos cuidar, ela via assim as pessoas vizinhas necessitadas e ela corria também. Então isso, para mim era uma novidade, eu tinha uns $9-10$ anos, e eu vi todo mundo contente, isso já deixou uma sementinha no meu coração. Quando eu crescer, depois de formar e tudo eu queria trabalhar nessa área". (V8)

A participação do cônjuge, principalmente a esposa, levou o companheiro a se tornar voluntário também: 
"A minha esposa participava e o convite foi estendido a mim. Eu vim e fiquei observando e aceitei participar. " (V6, V13)

"Então, acompanhando a minha esposa a gente viu que é melhor o idoso ficar mais na família do que em casa de repouso. " (V7)

\subsection{3.b GRATIDÃO}

Nessa subcategoria foram classificados os sentimentos de retribuição e agradecimento por ter algum familiar como usuário do projeto (Quadro 3).

"Quando surgiu o projeto eu logo pensei nas minhas tias que eram já dependentes, [...]. Eu preciso aproveitar essa oportunidade! Um projeto tão bom, né. Eles vão gostar. Daí eu parei e pensei: Peraí! Não posso só apresentar eu tenho que participar para ajudar, para servir, né. Foi a partir daí. Eu também tenho que fazer parte desse projeto. " (V14)

"Eu vi que a minha mãe só ficava em casa, não saia e eu via que ela estava ficando cada dia mais, (pausa), estava começando o Alzheimer, né. Aí resolvi trazer para cá [projeto] e como a minha mãe estava aqui, fiquei para ajudar, colaborar no que for possível. " (V10)

" [projeto] era para idoso, eu trouxe minha irmã para fazer entrevista com o sr Alberto. Ele explicou e ela ficou toda contente, daí no mesmo mês ela faleceu. Aí eu fiquei para ajudar na cozinha. No começo tinha 15 pessoas agora tem mais de 40. Nunca pensei em sair do projeto, só vou sair se me pedirem. " (V11)

Como vimos os discursos dos voluntários trouxeram uma riqueza de conteúdo, que muitas vezes se entrelaçavam nas categorias e subcategorias, dificultando a sua síntese. 


\section{DISCUSSÃO:}

\subsection{CARACTERÍSTICAS SOCIODEMOGRÁFICAS}

Ao entrevistar os 16 voluntários para conhecer os motivos que levaram os senescentes nipônicos a se tornarem voluntários no Projeto Lírios do Campos, encontramos uma predominância de mulheres em todas as faixas etárias, evidenciando que o processo mundial de feminização da velhice também, é uma realidade neste projeto, além do fato das mulheres terem mais facilidade em se associar para conversar, trocar experiências, fazer novas amizades, buscar ajuda e apoio nos momentos de dificuldade (Salgado, 2012;Vieira et al., 2015). Outra justificativa seria que habitualmente as mulheres são mais envolvidas nos contextos de trabalhos voluntários (Labegalini et al, 2015; Souza, Lautert, 2008).

Nesta população a maioria tinha nível superior completo, mostrando que a educação pode ser preditora do voluntariado, pois parece estimular a criticidade dos sujeitos a respeito dos problemas sociais e a aumentar o espírito cívico (Wilson, 2000).

Estar aposentado foi outra característica predominante neste grupo de senescentes nipônicos e, talvez, este seja um dos motivos de viabilidade do projeto, pois os voluntários podem empregar o tempo e o conhecimento adquirido ao longo da vida para manterem-se atuantes na sociedade. Uma pesquisa evidenciou que a maioria dos idosos, engajados em atividades voluntárias, são aposentados, isto pode estar relacionado, ao fato desses idosos possuírem uma vida financeira resolvida, dispor de tempo para exercerem outra atividade, sem a necessidade de proporcionar renda ou lucro financeiro (Souza, Lautert, Hilleshein, 2010).

Ao contrário do que encontramos na literatura, a minoria do grupo é composta por solteira, viúvas e separadas e destas, apenas duas moravam sozinhas. Outros estudos, mostram que a maior parte dos voluntários eram compostas por mulheres sem companheiros, por terem maior expectativa de vida e de viverem sós na velhice (Nesbit, 2012; Labegalini et al, 2015). 
Todos os participantes eram cristãos evangélicos praticantes, pertencentes a Igreja Metodista Livre e procuravam viver suas vidas de acordo com os preceitos bíblicos. Por serem japoneses ou descendentes de japoneses, o fato de ser cristão é raridade. No Japão, o Xintoísmo representa $84 \%$, seguido pelo Budismo com $71,5 \%$ e, o Cristianismo, representa apenas $2 \%$ da população (Japão, 2013), sendo apenas $0,35 \%$ cristãos evangélicos (IBL, 2011). Para o japonês, próspero, tecnológico e independente, terminologias como perdão e salvação não fazem sentido. Ele não crê que precisa ser salvo. Afinal, o japonês: vive a vida perfeita (IBL, 2011).

A religiosidade e a espiritualidade foram preditores positivos do trabalho voluntário, fornecendo o caminho, motivação e vontade para a pessoa tornar-se voluntária (Okun, Johnson, 2015). Dessa forma, os indivíduos, que frequentam igreja, têm maiores probabilidades de fazerem voluntariado do que os nãofrequentadores (Choi, 2003; Souza, 2008).

\subsection{ESTADO DE SAÚDE:}

A percepção de saúde para esta população, foi regular para mais da metade dos senescentes, sendo considerada boa para pouco mais de um terço deles, como pode-se perceber a autopercepção da saúde não é mais considerada meramente impressão relacionada às condições reais de saúde. Estudos têm mostrado que os indivíduos, que percebem sua saúde como positiva, têm risco de mortalidade consistentemente menor que aqueles que reportam pior estado de saúde (Anderson, et al,1998; Lebrão, Laurenti, 2003).

Apesar da maioria dos voluntários referirem algum tipo de doença, esses voluntários buscavam sentir-se úteis, como aponta estudos internacionais onde o trabalho voluntário esteve associado à maior longevidade dos indivíduos, com redução no risco de mortalidade em comparação aos não-voluntários (Lum, Lightfoot, 2005; Stessman, $\mathrm{H}$ et al 2005; Windsor, Anstey, Rodgers, 2008). Portanto a presença de doenças não é fator limitante para participar do trabalho voluntário ao contrário, o voluntariado está associado a maior longevidade. 
Alguns voluntários tinham diagnóstico de depressão, Síndrome do Pânico e faziam uso de medicações para humor, contudo estes agravos não interferiam nas atividades desenvolvidas no projeto e, inclusive, pela sensação de utilidade eram bastante assíduos. Estudos comparando idosos voluntários e não voluntários demostraram que houve um alto grau de bem-estar psicológico no grupo de voluntários (Bukov, Lampert, 2002; Mundaca, Gutierrez, 2014; Siervers, 1990; Windsor, Anstey, Rodgers, 2008), comprovando que ser voluntário é um meio importante de auto promover a saúde, levando-os ao bemestar psicológico.

Todos os voluntários que cuidavam diretamente dos idosos apresentaram escores altos no MEEM (29-30 pontos), até pelo alto grau de escolaridade, mas por estarem diretamente ligados aos cuidados de idosos limitados, não deveriam tem déficits de memória. Apenas uma voluntária da cozinha apresentou escore de 23 sugestivo de falhas de memórias, inclusive percebido por ela, mas que não influenciava nas suas atividades e nem colocava em risco sua participação, pois sempre esteve acompanhada pelas outras voluntárias em suas atividades.

\subsection{PERCEPÇÃO SOBRE O ENVELHECIMENTO:}

A concepção de velhice foi marcada por aspectos cronológicos, físicos, psicológicos, comportamentais, presença de doença, dependência, incapacidade e espiritualidade.

A forma de vivenciar a velhice é influenciada pela cultura da terra natal, mas guarda relação com as condições de vida, a valorização do trabalho, os preceitos religiosos e os laços/relações familiares. Vivenciar a velhice, para além dos aspectos culturais, considera suas experiências e interações ocorridas ao longo dos anos e que, conforme o contexto e o momento de vida, ganham contornos significativos (Brasil, 2014; Faller, Teston, Marcon, 2015).

Embora esse processo constitua um fenômeno inerente ao ser humano, a vivência dessa fase e a forma como as pessoas idosas representam o seu próprio processo de envelhecimento, são influenciadas pela interação de vários aspectos como os psicossociais, históricos, políticos, econômicos, geográficos e culturais e, mais especificamente, por diferenças relacionadas ao contexto de 
vida cotidiana, às crenças e às características pessoais, tornando-o particular a cada idoso. Acredita-se que há uma relação direta entre a concepção da velhice na sociedade em que se está inserido e o indivíduo que está envelhecendo (Medeiros, Santos, Sousa, et al, 2016; OPAS, 2006).

Os senescentes do projeto Lírios do Campo, de uma forma geral, tinham uma percepção do envelhecimento negativa, mas tinha uma visão positiva do próprio envelhecimento. Porém, quase metade apontaram uma visão realista do envelhecimento vivido e esperado. Embora tenham semelhanças no aspectos culturais e crenças, as diferenças de visões entre os voluntários, sobre o envelhecimento, ocorreram de modo individual.

Percebe-se que para o idoso voluntário a incapacidade funcional está relacionada a dependência física, presença de doenças e diminuição de memória, fato este que pode estar relacionado ao convívio com os idosos nessas condições, no projeto. Nesse sentido a incapacidade funcional poderia significar o retrocesso desses senescentes, a base da pirâmide de Maslow, referente às necessidades humanas básicas (Maslow,1970). A perda da funcionalidade contribui significativamente para o comprometimento da qualidade de vida da pessoa idosa, de seus familiares e cuidadores. Tanto que representa 0 condicionante mais importante de desfechos desfavoráveis na pessoa idosa, como hospitalização, institucionalização e morte.

A presença de doenças crônicas que levam a incapacidade funcional reforçam o estigma da velhice associada a dependência e, muitas vezes, é relatada pelo próprio idoso, inclusive por aqueles que não se consideram idosos. Nesses casos, ao mesmo tempo em que eles lançam mão de estratégias para negar a sua condição, passam a visualizar o velho no outro, o que evidencia a negação da velhice, cuja percepção, a partir do que se observa no outro, está associada a perdas, doenças e incapacidades, não se enquadrando no que eles visualizam em si. (Guerra, Caldas, 2010).

Um estudo sobre a percepção do idoso frente a velhice revelou o próprio envelhecimento como prenuncio de dependência e solidão, ressaltando que envelhecer traz a necessidade de ser cuidado por outro (Medeiros et al, 2016). 
Em contrapartida, quando houve percepção positiva sobre o próprio envelhecimento, esta foi marcada pela independência física, felicidade, com posturas agradáveis, carinhosos e obedientes a Deus.

Evidencia-se que a realidade encontrada com estes senescentes, está de acordo com o que a literatura vem afirmando, onde é possível envelhecer com saúde e qualidade de vida (Medeiros, et al, 2016).

A Política Nacional de Saúde da Pessoa Idosa, na sua versão de 2006, estabelece como meta a atenção à saúde adequada e digna para os idosos brasileiros, considerando a condição de funcionalidade, entendendo que a incapacidade funcional e as limitações físicas, cognitivas e sensoriais não são consequências inevitáveis do processo de envelhecimento, embora a prevalência de incapacidade aumente com a idade, esse fator sozinho não prediz incapacidade (Brasil, 2006).

Contudo o envelhecimento pode ser considerado, ainda, como um processo sequencial, individual, cumulativo, irreversível, universal, não patológico, de deterioração de um organismo maduro, próprio a todos os membros de uma espécie, de maneira que o tempo o torne menos capaz de fazer, frente ao estresse do meio ambiente; aumentando, portanto, sua possibilidade de morte (OPAS, 2006). Dessa forma, o envelhecimento vivido é algo bem particular, individual e complexo.

O envelhecimento ativo e a longevidade ajudam na preservação da capacidade cognitiva e inteligência, fatores psicológicos que podem ser naturalmente diminuídos pelo processo natural de envelhecimento. O declínio cognitivo do idoso possui várias causas, contudo, a motivação, valorização e gratificação social, além do estímulo cognitivo e social proporcionado pelo trabalho voluntário são protetores para um envelhecimento ativo e saudável (OPAS, 2005). Neste sentindo, os senescentes do projeto com suas percepções positivas acerca do próprio envelhecimento, estão na direção certa como voluntários, para alcançar o envelhecimento ativo e saudável.

Essa percepção positiva sobre o próprio envelhecimento, apresentada por esses idosos nipônicos pode estar relacionada a sensação de utilidade que 
segundo Sievers (1990), reflete no trabalho desenvolvido, a sensação de ser útil para o proximo, trazendo um significado para sí e de certa forma para Deus.

\subsection{PERCEPÇÕES SOBRE O VOLUNTARIADO:}

O voluntariado, é considerado como uma atividade de alto impacto positivo devido ao processo de aprendizagem que advém com suas atividades educativas, uma vez que trabalha junto com a participação de familiares e de demais pessoas da comunidade gerando verdadeiras transformações, além de ser uma fonte de auto realização (Braga, Mello, 2014).

Os significados capturados a partir das entrevistas com os senescentes foram relacionados em sua maioria ao altruísmo, como ajudar o próximo, contribuir com a sociedade e compartilhar experiências. Estes significados podem estar relacionados ao terceiro e quarto níveis da pirâmide de Maslow (1970) necessidades sociais ou afetivo-social e necessidades de status ou autoestima respectivamente. As atividades altruístas têm um forte impacto positivo na satisfação e no bem-estar da vida, e a participação em atividades sociais produtivas dá aos indivíduos sentimentos de realização pessoal e respeito por si mesmos (Bukov, Lampert, 2002, Maslow, 1970 e Sievers, 1990)

Também foram mencionados sentir-se útil e ocupar o tempo. $\mathrm{O}$ trabalho voluntário parece proporcionar, então, o encontro de pessoas com o mesmo propósito. Logo, manifesta-se um sentimento de estar envolvido em uma ação conjunta, com benefícios bidirecionais: tanto para quem faz, quanto para quem recebe (Dal Rio, 2004; Souza, Lautert, Hilleshein, 2010). Sentir-se útil estaria no topo da pirâmide de Maslow (1970) composta pela necessidade de auto realização, autodesenvolvimento contínuo e realização do próprio potencial. 0 estabelecimento de uma relação de benefícios bidirecionais para os senescentes nipônicos é que o trabalho voluntário é percebido como uma parte da vida individual e coletiva e não unicamente como um Projeto empregador (Sievers, 1990).

As três categorias apreendidas a partir dos relatos sobre os motivos pelos quais os senescentes tornaram-se voluntários, mostram a centralidade em Deus, 
pelo fato de todos os participantes serem cristãos evangélicos, como já apresentado Deus se revela na tríade Deus Pai, Filho e Espírito Santo, onde Jesus Cristo é o Filho que veio nos salvar e nos reconciliar com Deus através de sua morte na cruz e ressurreição. Ele é o nosso Salvador e o único mediador perfeito entre Deus e nós (Igreja Metodista Livre Concílio Nikkey, 2011).

O Espírito Santo é agente ativo em nossa consciência do pecado, é a vida da igreja e seu poder para testemunhar. Ele concede o amor de Deus e torna real o senhorio de Jesus Cristo no crente, de tal modo que tanto seus dons de palavras como de serviços possam alcançar o bem comum e edificar e aumentar a igreja. Em relação ao mundo, Ele é o Espírito da verdade e Seu instrumento é a Palavra de Deus (Igreja Metodista Livre Concílio Nikkey, 2011).

Um versículo Bíblico que pode retratar quem é Deus, encontra-se no Novo Testamento e diz assim:

\footnotetext{
"O Deus que fez o mundo e tudo o que nele há é o Senhor dos céus e da terra e não habita em santuários feitos por mãos humanas. Ele não é servido por mãos de homens, como se necessitasse de algo, porque ele mesmo dá a todos a vida, o fôlego e as demais coisas. De um só fez ele todos os povos, para que povoassem toda a terra, tendo determinado os tempos anteriormente estabelecidos e os lugares exatos em que deveriam habitar. Deus fez isso para que os homens o buscassem e talvez, tateando, pudessem encontrá-lo, embora não esteja longe de cada um de nós. Pois nEle vivemos, nos movemos e existimos [...]" Atos 17:24 -28
}

Servir a Deus e disseminar o Evangelho são papeis fundamentais do cristão e contribuir para a expansão do Reino de Deus na Terra, remete o trabalho voluntário ao sentido de vida para o cristão. Neste ponto, Sievers (1990) estabelece uma relação entre o sentido do trabalho e da vida, onde o significado do trabalho só pode ser compreendido além do referencial da vida e precisa ser qualificado a partir da realidade da finitude humana, para dar sentido a sua utilidade. Para os voluntários cristãos, Deus é o referencial da Vida Eterna e esse é o foco que o trabalho voluntário exerce.

O Projeto em si, trás o sentimento de pertencimento, além do sentimento de utilidade experienciado por estes idosos, que independentes da área de atuação, reúnem-se para planejamento, treinamentos, artesanatos em geral, passeios e 
orações, de forma que o trabalho não seja fragmentado e todos os voluntários se sintam parte do projeto. Este sentimento de pertencimento na cultura nipônica, tem valores sociais e emocionais importantes (Lima, 2012).

Estes aspectos vão ao encontro a teoria da motivação, pois segundo Maslow (1970), após alcançada a satisfação das necessidades básicas e de segurança, o indivíduo busca as necessidades sociais ou afetivo-social; de status ou autoestima e de auto realização, nesta ordem, como foram apreendidas nos discursos desses voluntários evangélicos.

O bom relacionamento em grupo também, foi relatado como forma de pertencimento e, também, reflete a herança deixada pela cultura japonesa onde o foco é a coletividade e para isso, a harmonia do grupo vem em primeiro lugar. Sem esse espírito de coletividade, o Japão não teria evoluído e nem se reerguido tão rápido diante de todas as catástrofes que já passou (Kawanami, 2014).

Valores relacionados aos sentimentos e inspirações familiares, foram expressos como uma forma de gratidão e retribuição ao passar esses valores adiante. Os discursos dos voluntários nipônicos citavam figuras femininas da família, especialmente a mãe, como inspiradora e motivadora da participação no projeto. A sociedade japonesa tende a valorizar o grupo ao invés do indivíduo e a família, neste caso, seria um grupo onde a mulher foi designada para ser a líder, cuidando do bem-estar do marido, dos filhos, das finanças da família e sendo responsáveis também pelo okozukai (subsídio ao marido). Ao marido cabe trabalhar fora e arcar com os gastos que uma família demanda, por isso os pais estão quase sempre ausentes (Kawanami, 2014).

A retribuição é um conceito muito importante para a sociedade japonesa e significa um "dever social" e consiste na obrigação de retribuir às pessoas que Ihe deram alguma coisa ou lhe prestaram algum favor. Historicamente os samurais tinham a obrigação de devolver favores aos outros como forma de manter a harmonia e a cordialidade em suas relações humanas e sociais (Lima 2012; Kawanami, 2015). Os voluntários nipônicos descreveram a retribuição como forma de agradecimento por terem familiares usufruindo do Projeto e até mesmo uma gratidão por estarem se beneficiando através das atividades e das relações sociais adquiridas no Projeto. O sentimento de gratidão é levado muito a sério e faz parte da conduta japonesa que é muito hierárquica e as pessoas 
tem uma grande preocupação de mostrar uma conduta amigável diante dos seus pares.

Como vimos, para estes voluntários evangélicos senescentes nipônicos, as principais motivações que levaram os idosos a ingressarem no voluntariado foram os sentimentos de altruísmo religioso (solidariedade, ajuda ao próximo, repartir, fazer o bem, servir de exemplo, melhorar o mundo, amor ao próximo e disseminar o evangelho) e o de ocupar o tempo livre, sentindo-se úteis à sociedade ao mesmo tempo em que melhoravam o convívio interpessoal, como apontam outros estudos no qual o compartilhar histórias de vida, questões pessoais e profissionais, trazem um ganho sócio-cultural, afetivo e espiritual (Souza, Lautert, Hilleshein, 2011 Braga, Mello, 2014; Mundaca, Zavala, 2014). 
6.CONSIDERAÇÕES FINAIS 


\section{CONSIDERAÇÕES FINAIS}

O projeto Lírios do Campo foi marcado pelo predomínio de idosos jovens com a maioria do sexo feminino, onde as mulheres têm papel fundamental, seja pela participação no voluntariado, seja no convite e na inserção dos maridos em atividades de voluntariado e até mesmo como fonte de inspiração para os senescentes participarem do projeto.

Os motivos que levaram os senescentes nipônicos a tornarem-se voluntários estão relacionados ao fato destes serem cristãos e terem Deus como sentido de vida. O projeto seria uma oportunidade de servirem a Deus, através de seu chamado, com o objetivo de evangelizar e converter os idosos japoneses. Apesar de Sievers (1990) apontar que o trabalho só pode ser qualificado a partir da finitude da vida, paras esses senescentes a finitude não seria a morte e sim o porvir com a Vida Eterna. Deus é o sentido da Vida para estes voluntários senescentes.

Apesar da subserviência herdada da cultura nipônica manifestada no modo como esses voluntários senescentes buscam servir a Deus através de sua participação no Projeto Lírios do Campo, pertencer ao projeto com visibilidade de serem referências de questões sobre idosos e cuidadores dentro e fora da igreja, leva a um sentimento de auto realização.

O ótimo relacionamento entre o grupo de voluntários e sentir-se útil, trazem benefícios bidirecionais, pois ajudam no convívio e participação social dos voluntários senescentes e ao mesmo tempo ajuda o outro e a sociedade, remetendo ao que atualmente os programas de envelhecimento saudável, preconizam.

Os valores atribuídos a vivência familiar e a retribuição, também, foram mencionados como motivadores para os senescentes ingressarem no voluntariado, pois sentirem-se aceitos, aprovados e de certa forma admirados, colaboram com o sentimento de autoestima.

Fazer a vontade de Deus seja respondendo ao Seu chamado ou disseminando o Evangelho, o pertencimento e o sentimento de sentir-se útil 
vinculado ao Projeto e, finalmente, os valores inspirados principalmente em figuras femininas da família, a gratidão e a retribuição foram os principais motivos que levaram os senescentes nipônicos se tornarem voluntários no Projeto Lírios do Campo.

$\mathrm{Na}$ literatura, sobre o trabalho voluntário japonês encontramos várias referências relacionados a grandes desastres naturais como os tsunamis e terremotos, mas poucas informações sobre o voluntariado direcionado especificamente aos idosos. Talvez porque cuidar dos idosos seja parte de uma cultura no qual esta atividade não seja classificada como um trabalho voluntário e sim como parte da cidadania, educação e respeito para a sociedade.

Outra dificuldade foi na busca de artigos sobre a cultura japonesa no Brasil, pois as literaturas existentes descrevem o processo e a trajetória de imigração, que não era objeto deste trabalho.

Vale salientar que este projeto, por estar vinculado a uma Instituição evangélica, onde o Amor é o estandarte das ações, possibilitou para muitos participantes externá-los com demonstrações de afeto e carinho, que é velada na cultura japonesa.

Do ponto de vista da Enfermagem, conhecer e participar de trabalho voluntário é enriquecedor por transcender o universo das instituições de saúde, focado nos processos de doença e incapacidades para além da promoção de saúde, onde é possível empoderar o idoso, permitindo que este continue útil e participativo na sociedade.

Mostra ainda, que o enfermeiro deve ter uma visão ampliada para a busca de um envelhecimento saudável, como preconiza a OMS, através de atividades coletivas nem sempre convencionais, considerando a sensação de utilidade que estas atividades devem proporcionar aos idosos. 


\section{REFERÊNCIAS BIBLIOGRÁFICAS}

Anderson MIP, Assis M, Pacheco LC, Silva EA, Menezes IS, Duarte T, et al. Saúde e qualidade de vida na terceira idade. Textos Envelhecimento [periódico na Internet]. 1998 [citado 2009 ago. 30];1(1):[cerca de 16 p]. Disponível em: http://www.unati.uerj.br/tse/scielo.php?script=sci_arttext\&pid=S1517$59281998000100003 \& \operatorname{lng}=$ pt\&nrm=iso

Andrade AN, Nascimento MMP, Oliveira MMD, Queiroga RM, Fonseca FLA, Lacerda SNB, et al. Percepção de idosos sobre grupo de convivência: estudo na cidade de Cajazeiras-PB. Rev bras geriatr gerontol. 2014 jan/mar 17(1):39-48.

Ação Voluntária. Ação voluntaria org. [internet]. Disponível em http://www.acaovoluntaria.org.br/vipexxonmobil/voluntario-historico.php.

Acesso: maio, 2016.

Angelo M, Bousso RS, Rossato LM, Damião EBC, Silveira AO, Castilho AMCM, Rocha MCP. Família como categoria de análise e campo de investigação em enfermagem. Rev Esc Enferm USP. 2009; 43(esp 2):1337-1341.

Bardin L. Analise de conteúdo. Lisboa: ed 70; 2011.

Beltrão KI, Camarano AA, Kanso S. Dinâmica populacional brasileira na virada do século XX. Rio de Janeiro: Instituto de Pesquisa Econômica Aplicada - IPEA, 2004. 71 p. (Texto para discussão, n. 1034). Disponível em: <http://www.ipea.gov.br/ portal/images/stories/PDFs/TDs/td_1034.pdf>. Acesso em: fev. 2016. ipea 2007

Berquó E. Considerações sobre o envelhecimento da população no Brasil. In: Néri AL, D GG. (orgs). Velhice e Sociedade. 2a. ed. Campinas, SP: Papirus; 2004.

Binder M, Freytag A. Volunteering, subjective well-being and public policy. J. Econ Psychol 34(1):97-119.2013.

Borges GM, Campos MB, Silva LGC. Transição da estrutura etária no Brasil: oportunidades e desafios para a sociedade nas próximas décadas. In: Mudança demográfica no Brasil no início do século XXI: subsidios para projeçoes da população. IBGE 2015; 138 -153.

Braga FM, Mello RR. Comunidades de aprendizagem e a participação educativa de familiares e da comunidade: elemento chave para uma educação de êxito para todos. Ed Unisinos. 2014mai/ago 1(2):165-175.

Bragança ABS. Aposentadoria: a experiência de professores aposentados do instituto de biologia da UNICAMP. Campinas: Unicamp, 2004.

Brasil. Ministério da Saúde; Organização Pan-Americana da Saúde; Organização Mundial da Saúde. Envelhecimento ativo: uma política de saúde. Brasília, 2005. 
Brasil. Política Nacional do Idoso. Lei 8.842, de 4 de janeiro de 1994. Declaração universal dos direitos humanos. Programa Nacional de direitos humanos. Brasília: Ministério da Justiça, Secretaria Nacional dos direitos humanos, 1998.

Brasil. Lei n 9.608, de 18 de fevereiro de 1998. Dispõe sobre o serviço voluntário e dá outras providencias. São Paulo:TRT/SP, 1998.

Brasil. Secretaria dos Direitos Humanos. Secretaria Nacional de Defesa dos Direitos Humanos. Dados sobre o envelhecimento no Brasil. Brasilia. Disponível em: www.sdh.gov.br acesso em março,2016.

Bukov A, Maas I, Lampert T. Social participation in very old age: cross-sectional and longitudinal findings from BASE. Berlin Aging Study. J Gerontol B Psychol Sci Soc Sci. 2002; 57(6): 510-7.

Camarano AA, Kanso S, Mello JL. Como vive o idoso brasileiro? In: CAMARANO, A. A. (Org.). Os novos idosos brasileiros: muito além dos 60? Rio de Janeiro: Instituto de Pesquisa Econômica Aplicada - IPEA, 2004. p. 25-73. Disponível

em: http://www.ipea.gov.br/portal/images/stories/PDFs/livros/Arq_29_Livro_Complet o. pdf>. Acesso em: fev. 2015camarano2004

Centro de Voluntariado de São Paulo. [internet] Disponível em: http://www.voluntariado.org.br/. Acesso: Abril 2016.

Choi LH. Factors affecting volunteerism among older adults. J Appl Gerontol. 2003;22(2):179-96.

Dal Rio MC. O trabalho voluntário: uma questão contemporânea e um espaço para o aposentado. São Paulo: SENAC; 2004.

Faça parte, Instituto Brasil Voluntário .[internet] Disponível em: http://www.facaparte.org.br. Acesso: maio 2016.

Faller JW, Ferraz TE, Marcon SS. A velhice na percepção de idosos de diferentes nacionalidades. Texto \& Contexto Enfermagem 201524128-137.2015 Disponible en: http://www.redalyc.org/articulo.oa?id=71438421016. Fecha de consulta: 27 de septiembre de 2017.

Fischer LR, Mueller DP, Cooper PW. Older volunteers: a discussion of the Minnesota Senior Study. Gerontologist; 31(2):183-94. 1991.

Guerra ACLC, Caldas CP. Dificuldades e recompensas no processo de envelhecimento: a percepção do sujeito idoso. Cienc Saude Colet. 2010 Set; 15(6):2931-40

Igreja Batista da Lagoinha (IBL). Japão, um olhar missionário 08/04/2011. Disponível em: http://www.lagoinha.com/ibl-vida-crista/japao-um-olharmissionario. Acesso 29/09/2017

Ikeda N, Saito E, Kondo N, Inoue M, Ikeda S, Satoh T, Wada K, Stickley A, Katanoda K, Mizoue T, Noda M, Iso H, Fujino Y, Sobue T, Tsugane S, Naghavi 
M, Ezzati M, Shibuya K. What has made the population of Japan Health? The Lancet 2011;378(9796): 1094-1105.

Ikegami N, Yoo BK, Hashimoto $H$, Matsumoto M, Ogata $H$, Babazono A, Watanabe R, Shibuya K,Yang BM, Reich MR, Kobayashi Y. Japanese universal helth coverage: evolution, achievements and challenges. The Lancet 2011; 378(9796): 1106-1115

Instituto Brasileiro de Geografia e estatística. Projeção da população no Brasil e nas unidades de federação. Disponível:

http://www.ibge.gov.br/apps/populacao/projecao/.2014.

Kawanami S. A importância da mulher na sociedade japonesa. Japão em foco

08/03/2014. Disponível em: http://www.japaoemfoco.com/a-importancia-damulher-na-sociedade-japonesa. Acesso: 01/10/2017

Kawanami S. A obrigação de demosntrar gratidão no Japão. Japão em foco 12/02/2015. Disponivel em: http://www.japaoemfoco.com/a-obrigacao-dedemonstrar-gratidao-no-japao. Acesso: 01/10/2017

Labegalini CMG, Uema RTB, Carreira L, Higarashi IH, Baldissera, VDA. O trabalho voluntario na pastoral da criança na terceira idade: repercussões pessoais. Rev. Pesq .cuid. fundam;7(3) 2726-2737. 2015.

Leandro-Franca C, Murta SG. Fatores de risco e de proteção na adaptação à aposentadoria. Psicol. Argum;32(76):33-43, PUCPR, 2014.

Lebrão ML, Laurenti R. Condições de saúde. In: Lebrão, ML, Duarte YAO, organizadores. SABE: Saúde, Bem-estar e Envelhecimento: o projeto SABE no município de São Paulo: uma abordagem inicial. Brasília: Organização PanAmericana de Saúde; 2003. p. 75-91.

Lima, IB. Reflexões sobre contemporaneidade cultural do Japão e seu legado histórico: clusters etnoculturais, aculturação e japonicidade. In: Saito, NIC et al.(Orgs). Japonicidades: Estudos sobre sociedade e cultura japonesa no Brasil central. Editora CRV: Curitiba, PR, Brasil, 2012 p 39-87

Lum TY, Lightfoot $E$. The effects of volunteering on the psysical and mental health of older people. Res Aging. 2005;27(1):31-55

Maslow, Abraham H. Motivation and personality. 2. ed. New York, Harper \& Row, 1970.369p.

McCurry Justin. Japan will be model for future super-ageing societies. The Lancet 2015;386(10003),1523.

Medeiros DV, dos Santos WL, Sousa MGM, Silva TCD, Silva PTP e Castro SFF. Percepção do idoso sobre a velhice Journal of Nursing UFPE online, 2016 Vol 10, No 10. 
Melo DM, Barbosa AJG. O uso do Mini-Exame do Estado Mental em pesquisas com idosos no Brasil: uma revisão sistemática. Ciênc. saúde coletiva [Internet]. 2015 Dec [cited 2017 Sep 29] ; 20( 12 ): 3865-3876. Available from: http://www.scielo.br/scielo.php?script=sci_arttext\&pid=S1413-

$81232015001203865 \& \operatorname{lng}=$ en. $\quad$ http://dx.doi.org/10.1590/1413812320152012.06032015

Minayo, MCS. Análise qualitativa: teoria, passos e fidedignidade. Ciência \& Saúde Coletiva, 17(3):621-626, 2012

Moniz ALF, Araújo TCCF. Trabalho voluntário em saúde: auto-percepção, estresse e burnout. Interação em Psicologia 2006 v10, №2.

Mundaca LF, Zavala G M. Bienestar Psicológico: Adultos mayores activos a través del voluntariado. Cienc. enferm. [Internet]. 2014 Abr [citado 2017 Oct 02] ; 20( 1 ): 123-130. Disponible en: http://www.scielo.cl/scielo.php?script=sci_arttext\&pid=S0717-

95532014000100011\&lng=es. $\quad$ http://dx.doi.org/10.4067/s071795532014000100011.

Musick MA, Wilson J. Volunteering and depression: the role of psychological and social resource in diferente age groups. Soc Med Sci. 56 (2): 259-69. 2003.

Néri AL. Maturidade e velhice: trajetórias individuais e socioculturais. Campinas: Papirus, 2001.

Okun MA, O'Rourker HP, Keller B, Johnson KA, Enders C. Value-expressive volunteer motivation and volunteering by older adults: relationships with religiosity and spirituality. J Geriatr. 2015; 70 (6): 860-870

Organização das Nações Unidas (ONU). Plano de Ação Internacional para o envelhecimento - 2002. Brasilia: Secretaria Especial dos Direitos Humanos; 2003.

Organização Das Nações Unidas (ONU): Relatório sobre envelhecimento alerta para 2050, ONU, 2009.

Paradela EMP, Lourenço R, Veras RP. Validação da escala de depressão geriátrica em um ambulatório geral. Rev. Saúde Pública; 39 (6): 918-923, 2005.

Reich MR, Ikegami N, Shibuya K, Takemi K. 50 Years of pursuing a healthy society in Japan. The Lancet 2011;378(9796):1051-1053.

Rheinberg, F. Motivation. Stuttgart: Kohlhammer.2000

Rosset I, Pedrazzi EC, Roriz-Cruz M, Morais EP, Rodrigues RAP. Tendências dos estudos com idosos mais velhos na comunidade: uma revisão sistemática (inter) nacional. Rev. Esc Enferm USP; 45(1): 264-71; 2011

Rudolph, U. Motivationspsychologie. Weinheim: Beltz. 2003 
Sabate RCD. Envelhecimento e Sociedade: Um debate sobre o lugar do idoso no Brasil contemporâneo. Marilia: UNESP, 2016.

Salgado, C. D. S. Mulher idosa: a feminização da velhice. Estudos Interdisciplinares sobre o Envelhecimento, v.4, p. 7-19, 2002.Disponível em:http://seer.ufrgs.br/index.php/RevEnvelhecer/article/view/4716/2642 Acesso em: 24/01/14.

Sievers, Burkard, Bergamini, Cecília W, \& Coda, Roberto. (1990). Além do sucedâneo da motivação. Revista de Administração de Empresas, 30(1), 0516. https://dx.doi.org/10.1590/S0034-75901990000100002

São Paulo. Manual de Assistência de enfermagem a saúde da pessoa idosa SMS/SP. Prefeitura do Município de São Paulo. 4ํo ed, 2012.

Souza LM. Trabalho voluntário: uma alternativa para promoção de saúde de idosos. Rev Esc Enferm USP;42(2):371-6. São Paulo, 2008.

Souza LM. Trabalho voluntário, saúde e qualidade de vida em idosos [dissertação]. Porto Alegre: Escola de Enfermagem, Universidade Federal do Rio Grande do Sul; 2007

Souza LM, Lauert L, Hillshein EF. Qualidade de vida e trabalho voluntário em idosos. Rev. Esc. Enferm.USP;45(3):665-71. São Paulo, 2011.

Stessman J, Hammerman-Rozenberg R, Maaravi Y, Azoulai D, Cohen A. Strategies to enhance longevity and independent function: the Jerusalem Longitudinal Study. Mech Ageing Dev. 2005;126(2):327-1.

Vieira AA, caldas TMS, Pio ES, KANSO S, A Feminização da Velhice: em foco as características socioeconômicas, pessoais e familiares das idosas e o risco social. Textos \& Contextos (Porto Alegre) 201514115-131. Disponible en: http://www.redalyc.org/articulo.oa?id=321540660010. Fecha de consulta: 28 de septiembre de 2017.

Who. World Health Organization. Envelhecimento ativo: uma política de saúde. World HealthOrganization: tradução Suzana Gontijo. Brasília: Organização PanAmericana da Saúde; 2005.

Wilson J. Volunteering. Annu Rev Sociol. 2000;26(2):215-40.

Windsor TD, Anstey KJ, Rodgers B. Volunteering and psychological well-being among young-old adults: how much is too much? Gerontologist. 2008; 48(1): 5970.

WORLD BANK. United Nations Department: World population.2015. Disponível em: http://esa.un.org/unpd/wpp/. 
APÊNDICES 


\section{APÊNDICE A - QUESTIONÁRIO DE COLETA DE DADOS}

\section{Características sócio demográficas:}

1.1 Nome (primeiras iniciais):

1.2 Endereço:

1.3 data de nascimento: ___ _ $/ 19 \ldots 1.4$ idade: ___ anos

\begin{tabular}{|c|c|}
\hline 1.4 Sexo: & $\square$ Masculino \\
\hline 1.5. Mora sozinho? & $\square$ Sim \\
\hline 1.6. Qual a sua cor? & $\square$ amarelo \\
\hline 1.7 Naturalidade: & Japão \\
\hline 1.8. Qual geração? & $\square$ 1geração $\square$ 2geração $\square$ 3geração \\
\hline 1.9 Estado civil: & $\begin{array}{l}\text { Solteiro } \square \text { casado } \square \text { separado/divorciado } \square \text { viúvo } \\
\text { Há quanto tempo com este status?..................................... }\end{array}$ \\
\hline 1.10. Tem filhos? & $\begin{array}{l}\square \text { Sim } \\
\text { Quantos? Não }\end{array}$ \\
\hline 1.11. Tem netos? & $\begin{array}{l}\text { Sim } \\
\text { Quantos? }\end{array}$ Não \\
\hline 1.12 com quem mora? & \\
\hline 1.13 Escolaridade: & $\square$ fundamental $\square$ ensino medio $\square$ superior $\square$ pos-graduação \\
\hline 1.14 Ocupação: & $\square$ trabalho remunerado $\square$ trabalha em casa $\square$ aposentado. \\
\hline $\begin{array}{l}1.15 \text { quanto tempo } \\
\text { está aposentado? }\end{array}$ & $\begin{array}{l}1-5 \text { anos } \square \text { 6-10anos } \square 11 \text { a } 15 \text { anos } \square 16 \text { a 20anos } \\
\text { Mais de } 21 \text { anos }\end{array}$ \\
\hline $\begin{array}{l}1.16 \text { Qual foi a última } \\
\text { área de atuação? }\end{array}$ & $\square$ Exatas $\square$ humanas $\square$ biológicas \\
\hline $\begin{array}{l}1.17 \text { Qual é a sua } \\
\text { religião? }\end{array}$ & $\square$ Evangélico $\square$ católico $\square$ outra $\square$ Não tenho \\
\hline $\begin{array}{l}1.18 \text { Qual é a } \\
\text { importância da religião } \\
\text { na sua vida? }\end{array}$ & $\square$ Muito importante $\square$ regular $\square$ pouco importante \\
\hline $\begin{array}{l}\text { 1.19. com que } \\
\text { frequência você vai a } \\
\text { igreja? }\end{array}$ & $\begin{array}{l}\square \text { 1-2x/semana } \square 1-2 \times / \text { mês } \square \text { em datas comemorativas } \\
\square \text { Raramente }\end{array}$ \\
\hline $\begin{array}{l}1.20 \text { Voce se esforça } \\
\text { para viver a sua vida } \\
\text { de acordo com suas } \\
\text { crenças? }\end{array}$ & $\square$ Concordo $\square$ concordo parcialmente $\square$ discordo \\
\hline
\end{tabular}




\section{Estado de saúde}

\begin{tabular}{|c|c|}
\hline $\begin{array}{l}2.1 \text { Você acredita que a sua } \\
\text { saúde é: }\end{array}$ & $\square$ Boa $\square$ regular $\square$ ruim \\
\hline $\begin{array}{l}2.2 \text { Comparando sua saúde } \\
\text { de hoje com a de } 1 \text { anos trás, } \\
\text { você diria que agora sua } \\
\text { saúde está: }\end{array}$ & $\square$ Melhor $\square$ igual $\square$ pior \\
\hline $\begin{array}{l}\text { 2.3.Comparando-se com } \\
\text { outras pessoas de sua idade, } \\
\text { você diria que sua saúde é: }\end{array}$ & $\square$ Melhor $\square$ igual $\square$ pior \\
\hline $\begin{array}{l}2.4 \text { Você tem alguma } \\
\text { doença? }\end{array}$ & $\square \operatorname{Sim} \quad \square$ Não \\
\hline 2.5 Qual (is) doenças? & $\begin{array}{l}\text { HAS } \square \text { DM } \square \text { dç cardíaca } \square \text { dç pulmonar } \\
\square \text { Dc articulares } \square \text { osteoporose } \square \text { outras } \\
\end{array}$ \\
\hline $\begin{array}{l}2.6 \text { Faz uso de algum } \\
\text { medicamento? }\end{array}$ & $\square$ Sim $\square$ Não \\
\hline 2.7 quais medicamentos? & $\begin{array}{l}1 . \\
3 . \\
5 .\end{array}$ \\
\hline $\begin{array}{l}\text { 2.8 Mini-exame do estado } \\
\text { Mental ( mini-mental) }\end{array}$ & $\begin{array}{l}\square 30 \text { pontos } \\
\square>=28 \text { (8 ou mais anos de escolaridade) } \\
\square<=24 \text { ( } 4 \text { a } 7 \text { anos de escolaridade) } \\
\square<=23 \text { ( } 1 \text { a3 anos de escolaridade) } \\
\square>=19 \text { (analfabeto) }\end{array}$ \\
\hline $\begin{array}{l}2.9 \text { Escala de Depressão } \\
\text { Geriátrica }\end{array}$ & $\square$ Menos de 5 pontos $\square$ mais de 5 pontos \\
\hline
\end{tabular}

\section{Percepção sobre envelhecimento:}

\begin{tabular}{|l|l|}
\hline 3.1 Cite três palavras que definam o & 1. \\
que o idoso é: & 2. \\
& 3. \\
\hline 3.2 Cite três palavras que & 1. \\
descrevam quando eu for idoso & 2. \\
serei: & 3. \\
\hline
\end{tabular}




\section{Percepção sobre trabalho Voluntariado e participação no Projeto}

\subsection{Para você, o que é ser voluntário?}

4.2. Exerce ou exerceu outro trabalho voluntário além desse? Qual? O que fazia? *Quanto tempo esteve ou está nesse outro voluntariado?

4.3 O que te levou a ser voluntario nesse projeto? * $E$ no outro?

4.4. Há quanto tempo está no Projeto Lírios do Campo?

$4.5 \mathrm{O}$ que faz no projeto?

4.6. Conte-me o que é mais difícil em sua atividade voluntária.

4.7 fale-me o que Ihe dá mais satisfação em sua atividade voluntária.

4.8. Me conte a sua história no projeto. Como ficou sabendo, como decidiu participar 


\section{APÊNDICE B - APÊNDICE B - TERMO DE CONSENTIMENTO LIVRE E ESCLARECIDO \\ Nome da Pesquisa: O SENESCENTE NIPÔNICO E O VOLUNTARIADO.}

\section{TERMO DE CONSENTIMENTO LIVRE E ESCLARECIDO}

Prezado (a) voluntário (a),

O (a) senhor (a) está sendo convidado a participar da pesquisa sobre os motivos que levam os senescentes nipônicos a tornarem-se voluntários em um projeto voltado para idosos com limitações, sob responsabilidade de Luciana Mitsue Sakano Niwa, aluna do curso de pós-graduação da Escola da Enfermagem da USP, orientada pela Profa. Dra. Suely Itsuko Ciosak.

Esse estudo tem por objetivos conhecer os motivos que os levaram a participar do Projeto Lírios do Campo. Para sua comodidade, a entrevista será realizada na igreja Metodista Livre da Saúde, após o término das atividades do Projeto Lírios do Campo. O tempo previsto para a entrevista e aplicação de escalas será de aproximadamente uma hora.

A entrevista pode apresentar pequena possibilidade de riscos ou prejuízos à sua saúde. Algumas pessoas gostam e se beneficiam de falar sobre a experiência como voluntários (as); outras podem não se sentir tão confortáveis. Então, por questões éticas, precisamos informar as vantagens/benefícios em participar da pesquisa; e dos riscos ou desvantagens.

Falar sobre a experiência vivida oferece a possibilidade de reorganizar os pensamentos, elaborar significados de sua experiência, trazer a lembrança momentos agradáveis, o que muitos consideram bastante proveitoso. Além disso, pode motivar outras pessoas a se envolverem em trabalhos voluntários. Os riscos que esta pesquisa oferece aos participantes estão relacionados exclusivamente ao campo do bem-estar emocional, por ser uma investigação sobre experiência vivida. Caso você sinta algum desconforto em compartilhar as informações durante a entrevista, você pode desligar o gravador ou recusar a responder. Havendo qualquer desconforto na participação, serão dados os devidos cuidados e encaminhamentos para a Unidade de Saúde da família mais próxima. Lembramos que sua participação é voluntária e a qualquer momento o 
(a) senhor (a) poderá deixar de participar desta pesquisa. A sua recusa não irá afetar a atuação no projeto.

Será solicitado que o (a) senhor (a) responda a algumas questões. Após este preenchimento, a pesquisadora fará uma breve entrevista que será gravada. As gravações serão transcritas e posteriormente descartadas. Todas as informações obtidas neste estudo, serão mantidas em sigilo e sua identidade não será revelada. Os resultados desta pesquisa serão divulgados em publicações científicas.

Caso o participante tenha alguma despesa decorrente de sua participação na pesquisa, o ressarcimento será feito pela pesquisadora, mediante comprovante como nota fiscal, por exemplo.

Caso haja eventuais danos decorrentes da pesquisa, o (a) senhor (a) terá direito a indenização.

Se você tiver alguma dúvida ou denúncia ética sobre esta pesquisa, entre em contato com o Comitê de Ética em Pesquisa (CEP) da Escola de Enfermagem da USP, telefone 30618858, e-mail - cepee@usp.br ou com a igreja Metodista Livre - Saúde (IMEL) - endereço - Rua Veriano Pereira, 52 - Saúde - São Paulo/SP CEP: 04144-030 Telefone: 2275-4812.

Em caso de dúvidas sobre a pesquisa, você pode entrar em contato com a pesquisadora Luciana Mitsue Sakano Niwa, Rua Enéas de Carvalho, telefone (11) 995-555-312 e-mail: lucianamsn@usp.br.

Este documento possui 2 (duas) vias, uma delas ficará com o(a) senhor(a) e a outra com a pesquisadora, e deverá ser rubricado em todas as páginas e assinado ambas as vias, de acordo com a Resolução 466/2012. 
Eu, , declaro ter sido informado e aceito participar, como voluntário, do projeto de pesquisa acima descrito.

São Paulo, de de

Assinatura do voluntário (a)

Assinatura da Pesquisadora 
ANEXOS 
Anexo A- Mini exame do estado Mental (Mini - Mental)

\begin{tabular}{|c|c|c|c|}
\hline $\begin{array}{l}\text { 1.Orientação } \\
\text { Temporal } \\
\text { (0-5 pontos) }\end{array}$ & Em que dia estamos? & $\begin{array}{l}\text { Ano } \\
\text { Semestre } \\
\text { Mês } \\
\text { Dia } \\
\text { Dia da semana }\end{array}$ & $\begin{array}{l}1 \\
1 \\
1 \\
1 \\
1\end{array}$ \\
\hline $\begin{array}{l}\text { 3. Orientação } \\
\text { espacial } \\
\text { (0-5 pontos) }\end{array}$ & Onde estamos? & $\begin{array}{l}\text { Estado } \\
\text { Cidade } \\
\text { Bairro } \\
\text { Rua } \\
\text { Local }\end{array}$ & $\begin{array}{l}1 \\
1 \\
1 \\
1 \\
1\end{array}$ \\
\hline $\begin{array}{l}\text { 4. Repita as } \\
\text { palavras } \\
\text { (0-3 pontos) }\end{array}$ & $\begin{array}{l}\text { Peça a pessoa para } \\
\text { repetir as palavras } \\
\text { depois de dizê-las repita } \\
\text { todos os objetos até que } \\
\text { o entrevistado o aprenda } \\
\text { (máximo de } 5 \\
\text { repetições) }\end{array}$ & $\begin{array}{l}\text { Caneca } \\
\text { Tijolo } \\
\text { Tapete }\end{array}$ & $\begin{array}{l}1 \\
1\end{array}$ \\
\hline 5. Cálculo & O sr. (a) faz cálculos? & $\begin{array}{l}\text { SIM (vá para 4.a) } \\
\text { NÃO (vá para 4.b) }\end{array}$ & \\
\hline $\begin{array}{l}\text { 4.a. Cálculo } \\
\text { (0-5 pontos) }\end{array}$ & $\begin{array}{l}\text { Se de } R \$ 100,00 \text { fossem } \\
\text { tirados } R \$ 7,00 \text {, quanto } \\
\text { restaria? E se tirarmos } \\
\text { mais } R \$ 7,00 \text { ? (total } 5 \\
\text { subtrações) }\end{array}$ & $\begin{array}{l}93 \\
86 \\
79 \\
72 \\
65\end{array}$ & $\begin{array}{l}1 \\
1 \\
1 \\
1 \\
1\end{array}$ \\
\hline 4.b. & $\begin{array}{l}\text { Soletre a palavra } \\
\text { MUNDO de trás para } \\
\text { frente }\end{array}$ & $\begin{array}{l}\mathrm{O} \\
\mathrm{D} \\
\mathrm{N} \\
\mathrm{U} \\
\mathrm{M}\end{array}$ & $\begin{array}{l}1 \\
1 \\
1 \\
1 \\
1\end{array}$ \\
\hline $\begin{array}{ll}\text { 6. } & \text { Memorização } \\
\text { 7. } & \text { (0-3 pontos) }\end{array}$ & $\begin{array}{l}\text { Repita as palavras que } \\
\text { disse há pouco }\end{array}$ & $\begin{array}{l}\text { Caneca } \\
\text { Tijolo } \\
\text { Tapete }\end{array}$ & $\begin{array}{l}1 \\
1 \\
1\end{array}$ \\
\hline $\begin{array}{l}\text { 8. Linguagem } \\
(0-2 \text { pontos) }\end{array}$ & $\begin{array}{l}\text { Mostre um relógio e uma } \\
\text { caneta e peça ao idoso } \\
\text { para nomeá-los }\end{array}$ & $\begin{array}{l}\text { Relógio } \\
\text { Caneta }\end{array}$ & $\begin{array}{l}1 \\
1\end{array}$ \\
\hline $\begin{array}{l}\text { 9. Linguagem } \\
\text { (1 ponto) }\end{array}$ & Repita a frase: & NEM AQUI, NEM ALI, NEM LÁ. & 1 \\
\hline
\end{tabular}




\begin{tabular}{|l|l|l|l|}
\hline $\begin{array}{l}\text { 10. Linguagem } \\
\text { (0-2 pontos) }\end{array}$ & $\begin{array}{l}\text { Siga uma ordem de três } \\
\text { estágios: }\end{array}$ & $\begin{array}{l}\text { Pegue o papel com a mão direita. } \\
\text { Dobre-o ao meio. } \\
\text { Ponha-o no chão }\end{array}$ & 1 \\
\hline $\begin{array}{l}\text { 11. Linguagem } \\
\text { (1 ponto) }\end{array}$ & $\begin{array}{l}\text { Escreva em um papel: } \\
\text { "feche os olhos". Peça a } \\
\text { pessoa para que leia a } \\
\text { ordem e execute }\end{array}$ & $\begin{array}{l}\text { FECHE OS OLHOS } \\
\text { (1 ponto) }\end{array}$ & $\begin{array}{l}\text { Peça a pessoa para } \\
\text { escrever uma frase } \\
\text { completa }\end{array}$ \\
\hline $\begin{array}{l}\text { 13. Linguagem } \\
\text { (1 ponto) }\end{array}$ & \begin{tabular}{l} 
Copie o desenho \\
\hline
\end{tabular} & 1
\end{tabular}

\section{PONTUAÇÃO MÁXIMA:}

- 30 pontos

- MAIOR ou IGUAL A 28 (8 ou mais anos de escolaridade)

- Menor ou igual 24 (4 a 7 anos de escolaridade)

- Menor ou igual 23 (1 a3 anos de escolaridade)

- Maior ou igual 18 (analfabeto) 


\section{Anexo B - Escala de Depressão geriátrica Yesavage}

\section{ESCALA DE DEPRESSÃO GERIÁTRICA}

1- Satisfeito(a) com a vida? (não)

2. Interrompeu muitas vezes suas atividades? (sim)

3. Acha sua vida vazia? (sim)

4. Aborrece-se com frequência? (sim)

5. Sente-se de bem com a vida na maior parte do tempo? (não)

6. Teme que algo ruim Ihe aconteça? (sim)

7. Sente-se alegre a maior parte do tempo? (não)

8. Sente-se desamparado(a) com frequência? (sim)

9. Prefere ficar em casa a sair e fazer coisas novas? (sim)

10. Acha que tem mais problemas de memória que outras pessoas? (sim)

11. Acha que é maravilhoso estar vivo(a) agora? (não)

12. Vale a pena viver como vive

agora? (não)

13. Sente-se cheio(a) de energia? (não)

14. Acha que sua situação tem solução? (não)

15. Acha que tem muita gente em situação melhor? (sim)

Quando a resposta: for diferente do exemplo entre parênteses $=0$ for igual ao exemplo entre parênteses $=1$ Total $>5$ = SUSPEIÇÃO DE DEPRESSÃO 


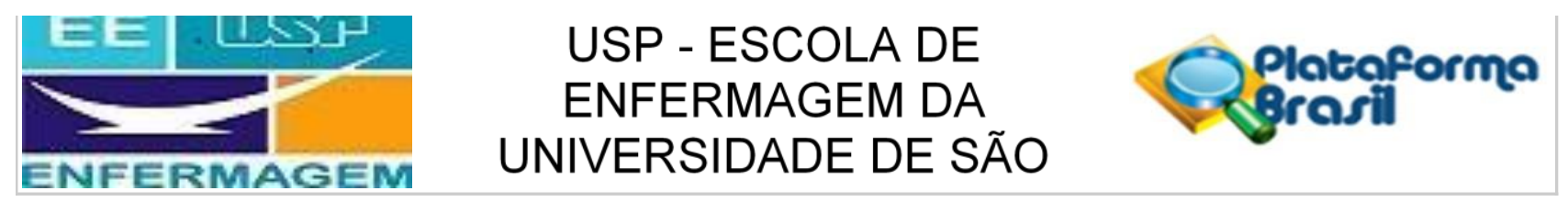

\section{PARECER CONSUBSTANCIADO DO CEP}

\section{DADOS DO PROJETO DE PESQUISA}

Título da Pesquisa: O Senescente Nipônico e o Voluntariado

Pesquisador: LUCIANA MITSUE SAKANO NIWA Área

Temática:

Versão: 4

CAAE: 61706316.9 .0000 .5392

Instituição Proponente:Escola de Enfermagem da USP

Patrocinador Principal: Financiamento Próprio

\section{DADOS DO PARECER}

Número do Parecer: 2.026.658

\section{Apresentação do Projeto:}

Foi pedido em relatoria anterior que os benefícios da pesquisa fossem modificados, por envolver apenas os participantes da pesquisa

\section{Objetivo da Pesquisa:}

OBJETIVO GERAL:

- Descrever os motivos que levaram os idosos de origem japonesa a exercerem atividades de voluntariadoem um projeto voltado para idosos.

\section{OBJETIVOS ESPECÍFICOS:}

- Descrever as características sócio demográficas dos idosos que exercem atividades de voluntariado.

- Conhecer a auto percepção dos voluntários, sobre a própria saúde.

- Identificar se os idosos voluntários se percebem como idosos.

- Identificar os fatores motivacionais do voluntariado com esse grupo de idosos.

Endereço: Av. Dr. Enéas de Carvalho Aguiar, 419

Bairro: Cerqueira Cesar

UF: SP Município: SAO PAULO

Telefone: (11)3061-8858

CEP: $05.403-000$

E-mail: cepee@usp.br 


\section{EE UWSP $\quad$ USP - ESCOLA DE \\ $>-1$ \\ ENFERMAGEM

Continuação do Parecer: 2.026.658

\section{Avaliação dos Riscos e Benefícios:}

Os benefícios foram alterados para:

Quanto aos benefícios que essa pesquisa pode proporcionar, o principal é o incentivo da participação de idosos em trabalhos voluntários. Para os participantes da pesquisa, falar sobre a experiência vivida oferece a possibilidade de reorganizar os pensamentos, elaborar significados de sua experiência, trazer a lembrança momentos agradáveis, o que muitos consideram bastante proveitoso. Por outro lado, outras podem não se sentir tão confortáveis.

\section{Comentários e Considerações sobre a Pesquisa:}

Em nova versão, os benefícios da pesquisa envolvem além dos participantes, a população em geral.

\section{Considerações sobre os Termos de apresentação obrigatória:}

Termos em conformidade com a Resolução 466/12

\section{Conclusões ou Pendências e Lista de Inadequações:}

A pendência apresentada em relatório consubstanciado anterior foi sanada.

\section{Considerações Finais a critério do CEP:}

- Este CEP informa a necessidade de registro de resultados parciais e finais na Plataforma Brasil

- Este parecer não substitui a autorização da instituição coparticipante, antes do início da coleta de dados.

\begin{tabular}{|l|l|c|l|c|}
\hline \multicolumn{1}{|c|}{ Tipo Documento } & \multicolumn{1}{|c|}{ Arquivo } & Postagem & \multicolumn{1}{c|}{ Autor } & Situação \\
\hline $\begin{array}{l}\text { Informações Básicas } \\
\text { do Projeto }\end{array}$ & PB_INFORMAÇÕES_BÁSICAS_DO_P & $29 / 03 / 2017$ & & Aceito \\
& ROJETO_810129.pdf & $29: 49: 57$ & & \\
\hline Projeto Detalhado / & Lucianapb.docx & $23: 44: 24$ & $\begin{array}{l}\text { LUCIANA MITSUE } \\
\text { SAKANO NIWA }\end{array}$ & Aceito \\
Brochura & & & & \\
Investigador & & $22 / 02 / 2017$ & LUCIANA MITSUE & Aceito \\
\hline TCLE / Termos de & tcleluf.docx & $21: 21: 18$ & SAKANO NIWA & \\
Assentimento / & & & & \\
Justificativa de & & & \\
Ausência & & $02 / 11 / 2016$ & LUCIANA MITSUE & Aceito \\
\hline Folha de Rosto & lucianapb.pdf & $19: 28: 22$ & SAKANO NIWA & \\
\hline
\end{tabular}

Este parecer foi elaborado baseado nos documentos abaixo relacionados:

Endereço: Av. Dr. Enéas de Carvalho Aguiar, 419

Bairro: Cerqueira Cesar

CEP: $05.403-000$

UF: SP Município: SAO PAULO

Telefone: (11)3061-8858

E-mail: cepee@usp.br 


USP - ESCOLA DE
ENFERMAGEM DA
UNIVERSIDADE DE SÃO

Continuação do Parecer: 2.026.658

Situação do Parecer:

Aprovado

Necessita Apreciação da CONEP:

Não

SAO PAULO, 22 de Abril de 2017

Assinado por:

Marcelo José dos Santos

(Coordenador) 
ANEXO 4

IGREJA METODISTA LIVRE - SAÚDE - CONCÍLIO NIKKEI

Rua Veriano Pereira, 52 - Saúde/SP - Cep 04144-030 - Tel.(11)22754812

CGC 53.587.242/0012-42 - Inscrição Estadual: isento

\section{$\underline{\text { AUTORIZAĈ̣̃O }}$}

Título: O senescente nipônico e o voluntariado

Pesquisadora: Luciana Mitsue Sakano Niwa

Orientadora: Prof ${ }^{a}$. Dra. Suely Itsuko Ciosak

Eu, Pastor Kodo Nakahara, autorizo a pesquisadora Luciana Mitsue Sakano Niwa a realizar a pesquisa junto aos voluntários do projeto Lírios do Campo, após a aprovação do Comitê de Ética em Pesquisa da Escola de Enfermagem da Universidade de São Paulo.

São Paulo, 24 de Outubro de 2016

Fraternalmente

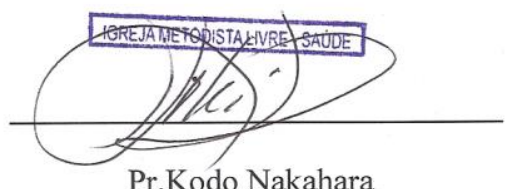

Pr.Kodo Nakahara 